\title{
Intercomparison of air ion spectrometers: an evaluation of results in varying conditions
}

\author{
S. Gagné ${ }^{1}$, K. Lehtipalo ${ }^{1}$, H. E. Manninen ${ }^{1}$, T. Nieminen ${ }^{1}$, S. Schobesberger ${ }^{1}$, A. Franchin ${ }^{1}$, T. Yli-Juuti ${ }^{1}$, J. Boulon ${ }^{2}$, \\ A. Sonntag ${ }^{3}$, S. Mirme ${ }^{4}$, A. Mirme ${ }^{4}$, U. Hõrrak ${ }^{4}$, T. Petäjä ${ }^{1}$, E. Asmi ${ }^{5}$, and M. Kulmala ${ }^{1}$ \\ ${ }^{1}$ Department of Physics, University of Helsinki, P. O. Box 64, 00014 Helsinki, Finland \\ ${ }^{2}$ Laboratoire de Météorologie Physique, Blaise Pascal Univ., 63000 Clermont-Ferrand, France \\ ${ }^{3}$ Leibniz Institute for Tropospheric Research, Permoserstrasse 15, 04303 Leipzig, Germany \\ ${ }^{4}$ Institute of Physics, University of Tartu, Ulikooli 18, 50090 Tartu, Estonia \\ ${ }^{5}$ Finnish Meteorological Institute, P. O. Box 503, 00101 Helsinki, Finland
}

Received: 16 November 2010 - Published in Atmos. Meas. Tech. Discuss.: 22 February 2011

Revised: 20 April 2011 - Accepted: 29 April 2011 - Published: 4 May 2011

\begin{abstract}
We evaluated 11 air ion spectrometers from Airel Ltd. after they had spent one year in field measurements as a part of the EUCAARI project: 5 Air Ion Spectrometers (AIS), 5 Neutral cluster and Air Ion Spectrometers (NAIS) and one Airborne NAIS (ANAIS). This is the first time that an ANAIS is evaluated and compared so extensively. The ion spectrometers' mobility and concentration accuracy was evaluated. Their measurements of ambient air were compared between themselves and to reference instruments: a Differential Mobility Particle Sizer (DMPS), a Balanced Scanning Mobility Analyzer (BSMA), and an IonDMPS. We report on the simultaneous measurement of a new particle formation (NPF) event by all 11 instruments and the 3 reference instruments. To our knowledge, it is the first time that the size distribution of ions and particles is measured by so many ion spectrometers during a NPF event. The new particle formation rates $\left(\sim 0.2 \mathrm{~cm}^{-3} \mathrm{~s}^{-1}\right.$ for ions and $\sim 2 \mathrm{~cm}^{-3} \mathrm{~s}^{-1}$ for particles) and growth rates $\left(\sim 25 \mathrm{~nm} \mathrm{~h}^{-1}\right.$ in the 3-7 nm size range) were calculated for all the instruments. The NAISs and the ANAIS gave higher concentrations and formation rates than the AISs. For example, the AISs agreed with the BSMA within $11 \%$ and $28 \%$ for negative and positive ion concentration respectively, whereas the NAISs agreed within $23 \%$ and $29 \%$. Finally, based on the results presented here, we give guidelines for data evaluation, when data from different individual ion spectrometers are compared.
\end{abstract}

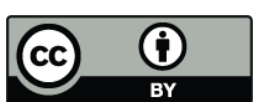

Correspondence to: S. Gagné (stephanie.gagne@helsinki.fi)

\section{Introduction}

Air ions have been studied extensively in the past both because of their influence on aerosol particle processes and because charged particles are easier to detect than neutral ones. Ions in the atmosphere influence aerosol particles through their formation and growth mechanisms (Laakso et al., 2002; Lovejoy et al., 2004; Kulmala et al., 2004), through cloud processes (Harrison and Carslaw, 2003), and scavenging of particles (Andronache et al., 2006). In turn, aerosols affect the Earth's climate and the health of its inhabitants (Twomey, 1991; Lohmann and Feichter, 2005; Myhre et al., 2009; Stevens and Feingold, 2009).

Measurements of charged atmospheric particles (air ions) are the basis of several aerosol measurement techniques (e.g. Gerdien counters, ion spectrometers, air conductivity measurement techniques; see Hirsikko et al., 2010). The charge of the particles can be used for their detection, and their electrical mobility for size classification. Other techniques rely on bringing the particles to a known charge equilibrium, allowing for the retrieval of the total particle concentration by data inversion. An example is the well-known and extensively used Differential/Scanning Mobility Particle Sizer systems (DMPS/SMPS, e.g. Wang and Flagan, 1990).

The ion spectrometers evaluated in this work have been developed by Airel Ltd. (Tartu, Estonia) based on longterm measurements and instrumentation development made at the University of Tartu (Matisen et al., 1992). The Air Ion Spectrometer (AIS) was first released in 2003 and measures the mobility distributions of small atmospheric ions and charged particles $(0.8-40 \mathrm{~nm}$ in mobility diameter at NTP, Mirme et al., 2007). Later, a second generation instrument

Published by Copernicus Publications on behalf of the European Geosciences Union. 
was released by the same company: the Neutral cluster and Air Ion Spectrometer (NAIS, Kulmala et al., 2007 and Manninen et al., 2009a). The NAIS can, in addition to the AIS operation modes (negative and positive ions), measure the total (neutral + charged) particle size distribution by using corona chargers to charge the particle population. An airtight and improved version of the NAIS, the Airborne NAIS (ANAIS, 2nd generation of NAIS, Mirme et al., 2010), was developed in 2007/2008 to allow measurements at different altitudes, including measurements on board an airplane. In this paper, results from all three different instrument types are presented.

New particle formation (NPF) and growth is an important phenomena and takes place frequently in different environments (see e.g. Kulmala et al., 2004). Previous measurements of NPF events were traditionally made using instruments capable of measuring only above $3 \mathrm{~nm}$, while the first steps of nucleation occur below this limit. The use of instruments such as the AIS and NAIS allowed for the detection of naturally charged particles and total (neutral and charged) particles below $3 \mathrm{~nm}$. This gives the possibility to observe the behavior of particles at the very first steps of nucleation (Kulmala et at., 2007).

The above mentioned ion spectrometers have been used in both field and laboratory measurements. They have been measuring, for example, on a trans-Siberian train (Vartiainen et al., 2007), indoors (Hirsikko et al., 2007), at a chamber experiment at CERN (Duplissy et al., 2010), on board an airplane (Mirme et al., 2010), and on field campaigns (see Hirsikko et al., 2010 and references therein). Between spring 2008 and spring 2009, the instruments were measuring at different EUCAARI stations (European Integrated Project on Aerosol Cloud Climate Air Quality Interactions; Kulmala et al., 2009; Manninen et al., 2010, Kerminen et al., 2010).

The first air ion spectrometer calibration workshop (Asmi et al., 2009) took place during January and February 2008 in Helsinki, Finland, where 10 instruments (5 AISs and 5 NAISs) were calibrated. The purpose of the first calibration workshop was to verify the accuracy of the instruments so that they can be compared after being deployed in different sites around the world. Another purpose was to help in the development of such instruments by thoroughly characterizing them. Asmi et al. (2009) performed mobility and concentration comparisons to reference instruments and compared the ion spectrometers to each other. They concluded that the 10 instruments were comparing well with each other and were accurate. They found that the theoretical transfer function used for data inversion was comparable to the one they measured for 1 AIS, and 3 NAISs. They also found that the ion spectrometers were slightly overestimating the mobility. Although they found that the NAISs showed larger concentrations than the AISs in ambient measurements, they did not find such a difference during calibrations.

One of the two main aims of the second air ion spectrometer calibration workshop (this work), was to investigate the repeatability of the measurements, after the instruments had spent about one year in varying weather conditions in different environments. The second aim was to compare the instruments to each other and to reference instruments more extensively using ion and particle concentrations that reflect the ones observed in the field, also during new particle formation events. The latter aims at producing guidelines for data analysis, especially when comparing ion spectrometers with each other.

In this paper, we present the calibration results for mobility and concentration, and discuss the differences and similarities to the first calibration workshop. We also discuss the results of the intercomparison as well as the comparison with other instruments: a Balanced Scanning Mobility Analyzer (BSMA, Tammet, 2006), a Differential Mobility Particle Sizer (DMPS, Aalto et al., 2001) and an IonDMPS (Laakso et al., 2007). We present the values obtained from NPF events and discuss the charged fraction measurements made with the different (A)NAISs. Thus we evaluate the performance of different instruments and provide guidelines for data analysis and interpretation of field and other measurements.

\section{Ion spectrometers}

All the ion spectrometers (AIS, NAIS, ANAIS) are based on the same principle and share the same mobility analyzer structure (Fig. 1). However, the models vary in their inlet part (including the chargers) and the air flow system (sampling and sheath air). It is to be noted that second generation NAIS models and the ANAIS have more than one blower. Each ion spectrometer is identified with an individual name which is built from the instrument type and its serial number (e.g. NAIS3, see Table 1 for a list). These names were used during the EUCAARI campaign as well as in this paper.

\subsection{Air Ion Spectrometer (AIS)}

The Air Ion Spectrometer (AIS, Mirme et al., 2007) measures the size distribution of charged particles with a high time resolution. The measured mobilities range between 3.2 and $0.0013 \mathrm{~cm}^{2} \mathrm{~V}^{-1} \mathrm{~s}^{-1}$, corresponding to Stokes-Millikan mobility diameters (Mäkelä et al., 1996) between 0.8 and $42 \mathrm{~nm}$ in NTP conditions. The AIS has two identical differential mobility analyzers (DMA) functioning in parallel: one for negatively charged particles and the other for positively charged particles. Each analyzer has a flow rate of $90 \mathrm{lpm}$ : $30 \mathrm{lpm}$ of sample flow, and $60 \mathrm{lpm}$ of closed loop sheath air flow. The sheath air is filtered for re-use by using a corona charger and an electrical filter. The sample air comes through a single inlet with a $60 \mathrm{lpm}$ flow which is then divided into two (30 lpm for each polarity). The high flow rate allows for smaller diffusional losses, so that low concentrations of smaller ions can be detected with a reasonable signal to noise ratio. The high time resolution of the instrument is 
Table 1. Tasks performed for each ion spectrometer. The signs + and - in the task represent positive and negative polarities, “-” means not done or not possible, and the "X" sign means that the task was performed. In the first two rows (standards and mobilities) the number of mobility standards used is shown on the left, and the number on the right expresses the total number of different mobility and concentration combinations.

\begin{tabular}{llllllllllll}
\hline & AIS1 & AIS2 & AIS3 & AIS6 & AIS7 & NAIS1 & NAIS2 & NAIS3 & NAIS4 & NAIS5 & A-NAIS \\
\hline + standards (nb. mob./conc.) & $4 / 12$ & $4 / 12$ & $4 / 15$ & $4 / 14$ & $4 / 23$ & $4 / 13$ & $-/-$ & $4 / 15$ & $4 / 15$ & $4 / 15$ & $4 / 10$ \\
- mobilities (nb. mob./conc.) & $-/$ & $4 / 10$ & $4 / 8$ & $4 / 10$ & $4 / 9$ & $4 / 8$ & $4 / 10$ & $4 / 9$ & $4 / 8$ & $4 / 10$ & $4 / 8$ \\
+ HDMA silver & - & $\mathrm{X}$ & $\mathrm{X}$ & - & $\mathrm{X}$ & - & - & $\mathrm{X}$ & $\mathrm{X}$ & $\mathrm{X}$ & $\mathrm{X}$ \\
- HDMA silver & - & $\mathrm{X}$ & $\mathrm{X}$ & - & $\mathrm{X}$ & - & - & $\mathrm{X}$ & $\mathrm{X}$ & $\mathrm{X}$ & $\mathrm{X}$ \\
+ HAUKE silver & $\mathrm{X}$ & $\mathrm{X}$ & $\mathrm{X}$ & $\mathrm{X}$ & $\mathrm{X}$ & $\mathrm{X}$ & - & $\mathrm{X}$ & $\mathrm{X}$ & $\mathrm{X}$ & $\mathrm{X}$ \\
- HAUKE silver & $\mathrm{X}$ & $\mathrm{X}$ & $\mathrm{X}$ & $\mathrm{X}$ & $\mathrm{X}$ & $\mathrm{X}$ & $\mathrm{X}$ & $\mathrm{X}$ & $\mathrm{X}$ & $\mathrm{X}$ & $\mathrm{X}$ \\
Neutral HAUKE silver & - & - & - & - & - & $\mathrm{X}$ & $\mathrm{X}$ & $\mathrm{X}$ & $\mathrm{X}$ & $\mathrm{X}$ & $\mathrm{X}$ \\
\hline
\end{tabular}

due to the design of its analyzers, which detect all mobility classes simultaneously, rather than by scanning the mobility distribution like in the SMPS or DMPS systems. The analyzers consist of an inner cylinder with 4 isolated sections to which different voltages are applied. The outer cylinder has 21 isolated cylindrical electrometers piled up vertically. The charged particles pass between the cylinders, perpendicular to an electric field, and are thus directed to an electrometer according to their electrical mobility. Each electrometer corresponds to a mobility channel and measures the current transmitted by these charged particles, from which their concentration is derived. The time resolution is user-adjustable but a minimum of one minute has been found to work with good accuracy, depending on noise levels (Asmi et al., 2009).

An offset measurement is made between each ion concentration measurement. A unipolar corona charger charges the particles with ions of the opposite polarity to that measured in the analyzer, and the charged particles are partly removed with an electric filter. During this operation mode, the electric field in the DMA is the same as for the other modes. This procedure allows for the measurement of air free of positively or negatively charged particles (for the positive or negative DMA, resp.) and thus the zero drift of the electrometers can be assessed as well as the RMS noise and noise due to parasitic currents. The offset is subtracted from the signal in the data inversion process. The data is inverted using the instrument equation of the ion spectrometer and the transfer function of the channels (based on geometry, flows, voltages and losses), and converted to a mobility distribution over 28 mobility bins. The inverting software is provided by Airel Ltd. It is also possible to record the raw electrometer electrical signal.

\subsection{Neutral cluster and Air Ion Spectrometer (NAIS)}

The Neutral cluster and Air Ion Spectrometer is an improved version of the AIS (Manninen et al., 2009a, Fig. 1). An additional charging-filtering section was added in order to measure the total number distribution of particles (the par- ticle mode module in Fig. 1). The sample (assumed to be at or close to the bipolar charge equilibrium) goes through a unipolar corona charger. The charged fraction of particles induced to the sampled air is known for all sizes (estimated from Fuchs theory, Fuchs and Sutugin, 1971). The corona ions (generally $<2 \mathrm{~nm}$ depending on concentration, air composition, polarity, etc.) are removed by the electrical filters, leaving a confidence size range between 2 and $42 \mathrm{~nm}$ (Asmi et al., 2009). The NAIS measures, in turn, the mobility distribution of particles (from negative and positive DMAs, particle measurements), and of naturally negatively and positively charged particles and ions (ion measurements), and the offset (offset measurements). The NAIS is also capable of measuring in the so-called alternative measurement mode, during which extra charging units, with the opposite polarity to the main charger, are turned on. This mode of operation should allow the retrieval of the total number concentration of particles even if the charge distribution of the particles in the atmosphere was not at charge steady-state. The alternative measurement operation mode was not used during the workshop.

\subsection{Airborne Neutral cluster and Air Ion Spectrometer (Airborne NAIS)}

The Airborne Neutral cluster and Air Ion Spectrometer (ANAIS, Mirme et al., 2009) is a second generation NAIS. It was developed to measure at varying altitudes (and thus pressures and temperatures). This was done by implementing an automatic sheath air flow adjustment system that compensates for the change in particle electrical mobility due to the change in pressure and temperature. The ANAIS has 3 or 4 blowers, depending on the model, to control the flows separately (one for the sheath air of the mobility analyzer and one or two connected in series for the sampling line), whereas first generation NAISs had only one central blower. The data acquisition system was also upgraded to adjust to the conditions so that the data is always adjusted to NTP conditions. The charger current in the corona charger is controlled 


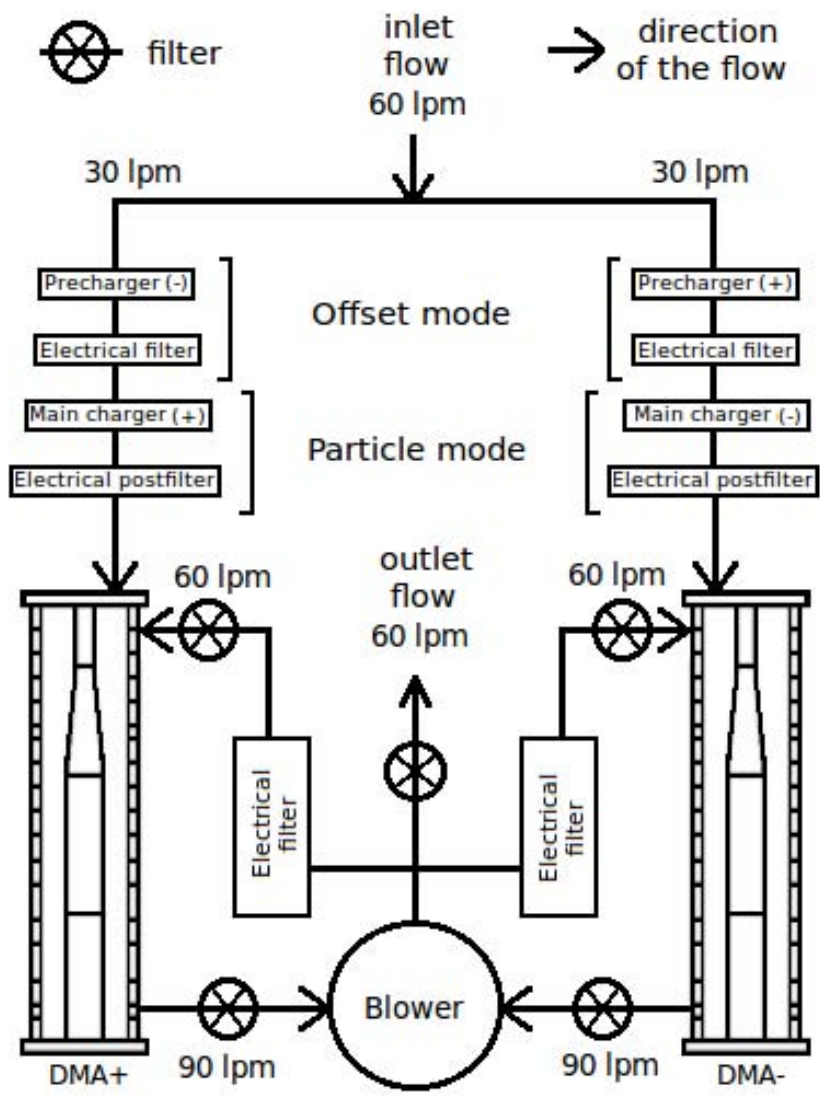

Fig. 1. Schematic figure of an NAIS. The inlet flow is $60 \mathrm{lpm}$ split into two, $30 \mathrm{lpm}$ for each polarity. The offset mode box is active only during the offset measurement mode; and the particle mode box is active only during the particle measurement mode. In the AIS, the particle mode box does not exist. The ANAIS has a different design with multiple blowers to control different parts of the flow.

to keep the efficiency of diffusion charging stable. All the changes were made to insure that the DMA parameters of the ion spectrometer remain constant and the same data inversion procedure can be used. A new, 2nd generation inversion program was also developed along with the instrument. This new version of the NAIS can be easily used in changing atmospheric conditions, and requires little maintenance.

\section{Measurement setups and procedure}

During the calibration period (25 May 2009-26 June 2009), we used mobility standards, silver ions and silver particles to investigate the measurements of mobility and concentration. The flows were also adjusted prior to the calibrations, to insure the accuracy of the comparison. In this section, we will describe the different experimental setups (or stations) used to calibrate the ion spectrometers. Four main stations can be distinguished: the flow adjustment station, the Hauke-type DMA station (4-40 nm particles), the High resolution DMA station (HDMA, $<5 \mathrm{~nm}$ particles), and the intercomparison station. The high resolution DMA setup allows for two different sub-setups: using mobility selected silver ions and mobility standards (Ude and Fernández de la Mora, 2005).

The Airborne NAIS as well as the AIS 2, which had not been calibrated in the first calibration workshop but participated in the EUCAARI measurement campaign, were calibrated for the first time. The AIS 5, that was present in the first calibration workshop, was not available this time. The same mobility and concentration calibration were performed on 5 AISs, 5 NAISs and the Airborne NAIS (ANAIS). The calibration procedures that were performed are summarized in Table 1.

\subsection{Flow adjustment setup}

When the instruments arrived in Helsinki, they were thoroughly cleaned and sent to the flow adjustment station to ensure the best mobility and concentration measurements. The different parts of the flow system were adjusted while keeping the sampling flow at $\sim 60 \mathrm{lpm}$. In all ion spectrometers, except the ANAIS, five flows share one central blower (Fig. 1). Each of those five flows were measured through the pressure drop in Venturi tubes, and adjusted if required. The flow balance was verified for leaks in the same fashion as described by Asmi et al. (2009), before sending the ion spectrometer further to mobility and concentration calibration. All the pressure drops had been stable during the field campaign, provided that the Venturi tubes were unobstructed, and only small adjustments were made. This means that, if maintenance cleaning is done regularly, the instruments can perform well for long periods in diverse field conditions.

\subsection{Hauke DMA}

One of the purposes of this station was to compare the mobility diameter measured with the ion spectrometers with the mobility diameter selected with a Hauke-type DMA $(10.9 \mathrm{~cm}$ in length, Winklmayr et al., 1991). Also, the concentrations given by the ion spectrometers was compared with a Condensation Particle Counter (CPC, TSI 3025, Stoltzenburg and McMurry, 1991) and an aerosol electrometer (TSI 3068A) as shown in Fig. 2a.

Polydisperse silver particles were produced with a tube furnace (Carbolite Furnaces MFT 12/388), then sent into a bipolar charger $\left({ }^{241} \mathrm{Am}\right)$ to get charged and then size selected with a DMA. The particle size varied between 4 and $40 \mathrm{~nm}$. The sample flow in the DMA was $4 \mathrm{lpm}$ and the sheath air flow was $20 \mathrm{lpm}$. To make up for the total sampling flow of the detection instrument (ion spectrometers $60 \mathrm{lpm}, \mathrm{CPC}$ : $1.5 \mathrm{lpm}$, and aerosol electrometer: $3 \mathrm{lpm}$ ), $63 \mathrm{lpm}$ of diluting air was introduced after the DMA. The $50 \%$ cut-off size of the CPC was $3 \mathrm{~nm}$, while the electrometer, in principle, detects all ions and charged particles with a noise level of about $\sim 300 \mathrm{~cm}^{-3}$. 
a) Hauke DMA setup

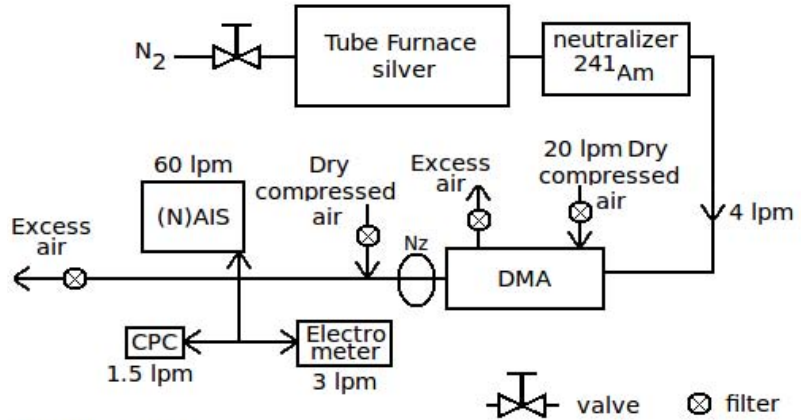

b) HDMA setup

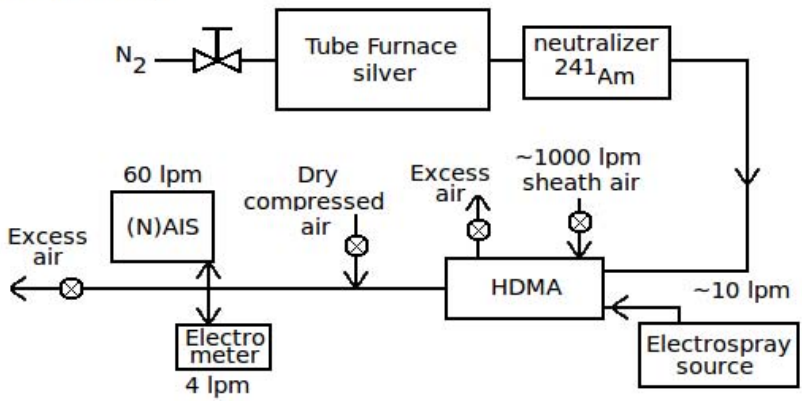

Fig. 2. Schematic figure of the setups used during the calibration procedure. The instruments and the most important flows are included for (a) Hauke setup, and (b) HDMA setup. The Hauke-setup includes a neutralizer $(\mathrm{Nz})$ for calibrations in particle measurement mode. The HDMA setup can be operated either with the furnace or the electrospray, not both at the same time.

The ion spectrometers were operated in two or three of their operation modes: ions, particles (in the case of NAISs only) and offset mode. Concentration and mobility measurements were made when the concentration or the mobility was kept stable over several measurement cycles of the ion spectrometers. We also performed measurements of the ion spectrometer transfer function in which the mobility was scanned stepwise, each step spanning over one complete measurement cycle. The mobility range varied between 0.0014 and $0.13 \mathrm{~cm}^{2} \mathrm{~V}^{-1} \mathrm{~s}^{-1}(\sim 4-40 \mathrm{~nm})$ and was divided over 100 size bins.

\subsection{High resolution DMA (HDMA)}

The high resolution DMA, or Herrmann DMA (HDMA, Eichler, 1997; de Juan and Fernández de la Mora, 1998, Ude and Fernández de la Mora, 2005; Herrmann et al., 2000) was used in mobility standard and silver ion calibrations as well as for transfer function measurements. The very high mobility resolution of the HDMA, due to its high sheath flow rate (more than $1000 \mathrm{lpm}$ ), allows for the very precise selection of the mobility and the use of small particle sizes $(<5 \mathrm{~nm})$. The width of the DMA transfer function is much smaller than the resolution of the ion spectrometers. The HDMA was cal- ibrated every day before starting the measurements, for establishing an accurate voltage to mobility conversion. The concentration was measured with an electrometer, in parallel with the ion spectrometers as shown in Fig. 2 b.

\subsubsection{Calibration with mobility standards}

Mobility standards were used for mobility calibration at particle sizes smaller than $3 \mathrm{~nm}$ in diameter. For producing positive standards, we used THAB (tetra-heptyl ammonium bromide) and TMAI (tetra-methyl ammonium iodide), and for negative mobilities only THAB was used. Those compounds were electrosprayed, producing singly charged ions with known mass and mobility (Ude and Fernández de la Mora, 2005). Four such positive ions and four negative ions were selected using the HDMA. Each peak was measured at different concentrations.

The mobilities of the positively charged standards were 2.18 (TMAI derived $\mathrm{TMA}^{+}$ions), 0.97, 0.65 and $0.53 \mathrm{~cm}^{2} \mathrm{~V}^{-1} \mathrm{~s}^{-1}$ (THAB derived $\mathrm{THA}^{+}$, (THAB) $\mathrm{THA}^{+}$ and (THAB $)_{2} \mathrm{THA}^{+}$, resp.) at NTP. The standards used here are the same that were used in the first calibration workshop and their values are well established.

Four mobility peaks were selected from the negative THAB spectrum as well, even though their composition has not been verified by mass spectrometry and their stability is not known. The mobilities of the peaks that were used are: 2.45 (most probably $\mathrm{Br}^{-}$ions), 1.48, 0.87 and $0.64 \mathrm{~cm}^{2} \mathrm{~V}^{-1} \mathrm{~s}^{-1}$.

\subsubsection{Calibrations with silver ions}

The transfer function of the ion spectrometers for small particles was also measured using silver ions, mobility-selected with a HDMA. The silver particles were produced using a tube furnace and charged downstream with a bipolar charger $\left({ }^{241} \mathrm{Am}\right)$ before entering the HDMA. Below about $2 \mathrm{~nm}$ in mobility diameter, the particles were probably a mixture of ions produced in the charger and silver particles. For positively charged particles, we selected 81 logarithmically spaced mobilities between 0.09 and $1.10 \mathrm{~cm}^{2} \mathrm{~V}^{-1} \mathrm{~s}^{-1}$ $(\sim 1.4-4.8 \mathrm{~nm})$. For negatively charged particles, the mobilities ranged between 0.38 and $1.48 \mathrm{~cm}^{2} \mathrm{~V}^{-1} \mathrm{~s}^{-1}(\sim 1.2-$ $2.3 \mathrm{~nm}$ ) separated over 51 mobility bins.

\subsection{Intercomparison}

The intercomparison took place in a classroom at the University of Helsinki Kumpula campus. The room was situated on the 4th floor of the physics building "Physicum". The room had a door leading to a large balcony and another one leading to a corridor with offices. The room's surface was about $42 \mathrm{~m}^{2}$ with a height of about $4 \mathrm{~m}$. When the door to the balcony was opened, the particle concentration rose rapidly. The ion spectrometers were measuring in this room whenever they were not being calibrated, in cleaning, or in 
repair. The ion spectrometers measured indoor air, or mixed indoor and outdoor air, and during new particle formation and growth. The NPF event was provoked by peeling citrus fruits in the middle of the room at approximately the same distance from each instrument. There was no additional fan system insuring that the air was well mixed, but all ion spectrometers were able to detect the new particle formation almost instantly and simultaneously. After each original event, secondary events always took place a few hours later in the same closed room.

\subsubsection{Accompanying instruments}

Three other instruments were measuring in the same room along with the AIS and NAIS ion spectrometers: a BSMA, a DMPS and an Ion-DMPS. In this section, we describe those three instruments.

The Balanced Scanning Mobility Analyzer (BSMA, Tammet 2006) measures the number size distribution of cluster ions and naturally charged particles in the size range $0.7-$ $7 \mathrm{~nm}$ (Stokes-Millikan mobility diameters). The BSMA consists of two parallel plane-type DMAs for negative and positive ion classification and one common electrical amplifier as a detector. Here, the detector measures the electrical currents of air ions. The BSMA measures negative and positive ion spectra one after the other - not simultaneously. Due to high electrometer sensitivity, high flow rates and small wall losses, the BSMA is typically used as a reference for small ion concentrations. The BSMA agrees well with other instruments (see e.g. Hirsikko et al., 2005; Kulmala et al., 2007; Manninen et al., 2009a and Ehn et al., 2010), .

The Differential Mobility Particle Sizer (DMPS, Aalto et al., 2001) measured the atmospheric aerosol particle number size distribution between 10 and $300 \mathrm{~nm}$ in diameter. The DMPS consisted of a Hauke-type DMA (length $28.0 \mathrm{~cm}$ ) in closed loop sheath flow arrangement (Jokinen and Mäkelä 1996), a CPC (TSI 3025, Stolzenburg and McMurry 1991) as a particle detector and a radioactive $\mathrm{C}-14$ alpha neutral$\operatorname{izer}(370 \mathrm{MBq})$. Sampled particles were charged in an alphaactive bipolar charger and classified according to their electrical mobility in the DMA. Subsequently, the classified particles were counted by a particle detector (CPC), and the total concentration was retrieved after standard DMPS inversion. The DMPS was not calibrated, but the transfer function of the DMA and the CPC cut off size were known from earlier calibration measurements.

The Ion-DMPS (Laakso et al., 2007) is identical to a DMPS, with the exceptions that its bipolar charger can be switched on or off and the voltage applied to the DMA can be either positive or negative. The Ion-DMPS thus measured in four modes: positively charged particles neutralized $(1 .+$ neu. $)$ or ambient $(2 .+\mathrm{amb}$.); negatively charged particles neutralized (3. - neu.) or ambient (4. - amb.). During the intercomparison, the Ion-DMPS was measuring particles between 2.2 and $11.5 \mathrm{~nm}$ in mobility diameter. The calibration curves of the instrument can be found in Laakso et al. (2007). This instrument was used as a reference instrument to compare the charged fraction, the fraction of particles that are charged in the particle distribution. The Ion-DMPS is designed to measure the charge ratio: the ratio of the ambient, "naturally" charged particle concentration to the neutralized (electrical bipolar steady-state) ion concentration. This quantity is equivalent to the ratio of the ambient charged fraction to the neutralized charged fraction. The NAIS measures the charged fraction: the ratio of the ion concentration to the total particle concentration. The neutralized charged fraction in the bipolar steady-state is known (Wiedensohler, 1988) so the charged fraction at ambient can be calculated from the Ion-DMPS charge ratio and compared to the charged fraction derived with the NAISs.

\section{Results and discussion}

The performance of the 11 ion spectrometers (5 AISs, 5 NAISs, one Airborne NAIS) was tested against reference devices and compared to each other (Table 1), after a one-year field measurement campaign. Also, all the instruments measured a NPF event simultaneously for the first time. In this section, we discuss the results from mobility and concentration calibrations as well as the intercomparison and the new particle formation event.

\subsection{Mobility, mobility standards and concentration calibrations}

All 11 ion spectrometers measured electrospray-generated mobility standards according to the method described in Sect. 3.3.1. Results from three examples of mobility standards of each polarity are presented in Fig. 3. The AISs and NAISs alike detected the mobility of the concentration peak almost accurately and compare well with each other. A shift can be observed with the $\mathrm{TMA}^{+}$ion (the smallest positive standard) and with negative standards. Part of the inaccuracies could result from clustering or fragmentation of the ions after mobility selection. All inaccuracies for negative standards point to an underestimation of the mobility, thus an overestimation of the size. Another observation that can be made on Fig. 3 is that the AISs display a sharper peak than the NAISs. This was also seen in the previous workshop, as shown by Asmi et al. (2009). The fact that normalized concentration peaks are broader for NAISs than for AISs could suggest that the NAISs detect small concentrations also in other size bins, in the ion measurement mode, that contribute to the total concentration. It could also be due to more turbulent flows in the NAISs than in the AISs, making particles land on the neighboring electrometers.

Figure 4 shows the results from the calibrations done with silver particles with the HDMA setup $(<5 \mathrm{~nm})$ and the Hauke-DMA setup $(4-40 \mathrm{~nm})$. In the first column, we 

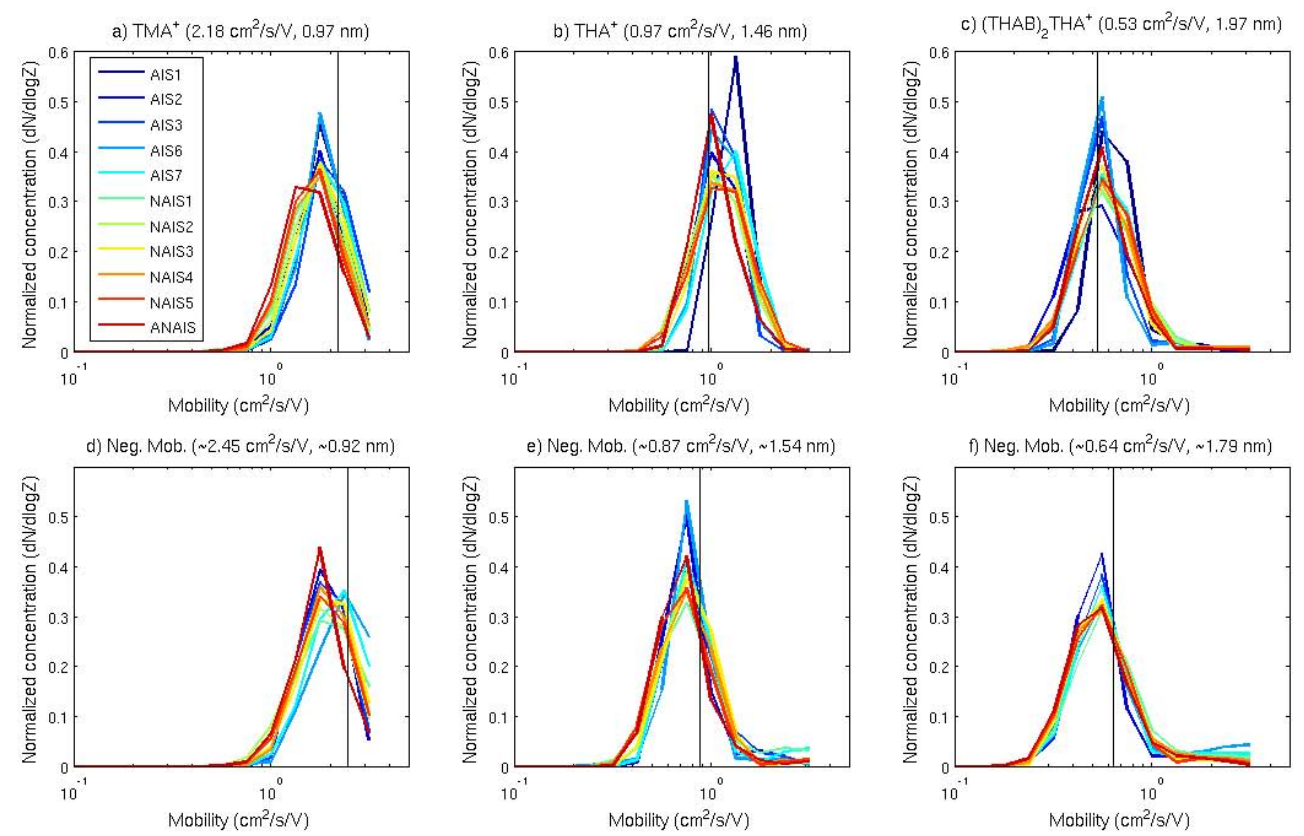

Fig. 3. Examples of mobility standards measurements. Panels (a), (b) and (c) show the response of the ion spectrometers (normalized mobility distribution) for 3 positively charged mobility standards, and panels (d), (e) and (f) for 3 negative mobilities. The black vertical lines represent the mobility that was selected through the HDMA. The mobility and size of the standards are above each plot. TMAI is tetra-methyl ammonium iodide and THAB is tetra-heptyl ammonium bromide.

compare the mobilities detected by the ion spectrometers (the peak of the mobility distribution) and the mobilities selected by the DMAs. In the second column, the concentrations seen by the ion spectrometers and the reference instruments are compared. Finally, in the third column, the ratio of the concentrations detected by the ion spectrometers and the reference instruments is shown as a function of the mobility. The first and second rows show the negative and positive ions, respectively. Background measurements are presented in Fig. 5. We used the DMA as a filter by applying a zero voltage so that the ion spectrometers were measuring particle-free air. In the following analysis, we will first focus on the ion data (first two rows in Fig. 4), then we will discuss the results from the particle mode (third row in Fig. 4).

In the ion measurement mode of the ion spectrometers, the peak mobilities were detected very accurately. In the positive mode at small diameters, however, the mobility was slightly overestimated. This was also observed by Asmi et al. (2009). In the second column of Fig. 4, the concentrations are compared to those measured with an electrometer. The concentration detection is rather good, but the NAISs overestimate the concentrations, and this is especially noticeable for the positive polarity. The concentration for the ion spectrometers in Fig. 4 is the total concentration integrating the whole size range of the instrument. In the third column, the ratio of the concentrations detected with the ion spectrometers to the electrometer concentration is shown as a function of mobility. The AISs and NAISs behaved similarly at larger diameters (smaller mobilities) but the NAISs overestimated the concentration at smaller diameters. The Airborne NAIS generally followed the behavior observed in first generation NAISs. One should note that the two setups cover different size ranges (Hauke DMA: $\sim 4-40 \mathrm{~nm}=0.0014-0.13 \mathrm{~cm}^{2} \mathrm{~V}^{-1} \mathrm{~s}^{-1} ; \quad$ HDMA: $\left.<\sim 5 \mathrm{~nm}=>0.083 \mathrm{~cm}^{2} \mathrm{~V}^{-1} \mathrm{~s}^{-1}\right)$. Hence, we have a gap for negative ions (the voltage supply only allowed for a smaller mobility range) and double lines for positive ions (the methods overlap on a small mobility range). The two methods are not in perfect agreement. This may be explained by that, at small sizes, the transfer function of the Hauke DMA is wider and the concentration of silver particles available is smaller. Thus the losses (and corrections) are more important in the Hauke setup than in the HDMA setup. One can see in the third column that the concentrations are overestimated more as the diameter decreases for both setups. Part of this overestimation can be due to the setup, since the ratio falls back to one when the setup changes from the Hauke DMA to the Herrmann DMA. However, despite corrections for losses in the experimental setups, the trend remains. In the left column of Fig. 5, one can see the background of the ion spectrometers in ion measurement mode as a function of diameter. The median total background concentration was $13.6(23.5) \mathrm{cm}^{-3}$ for AISs and $71.7(53.2) \mathrm{cm}^{-3}$ for NAISs for negative (and positive) ions. The background could partly be caused by ionization through radioactive decay or cosmic rays in the inlet of the instrument. 

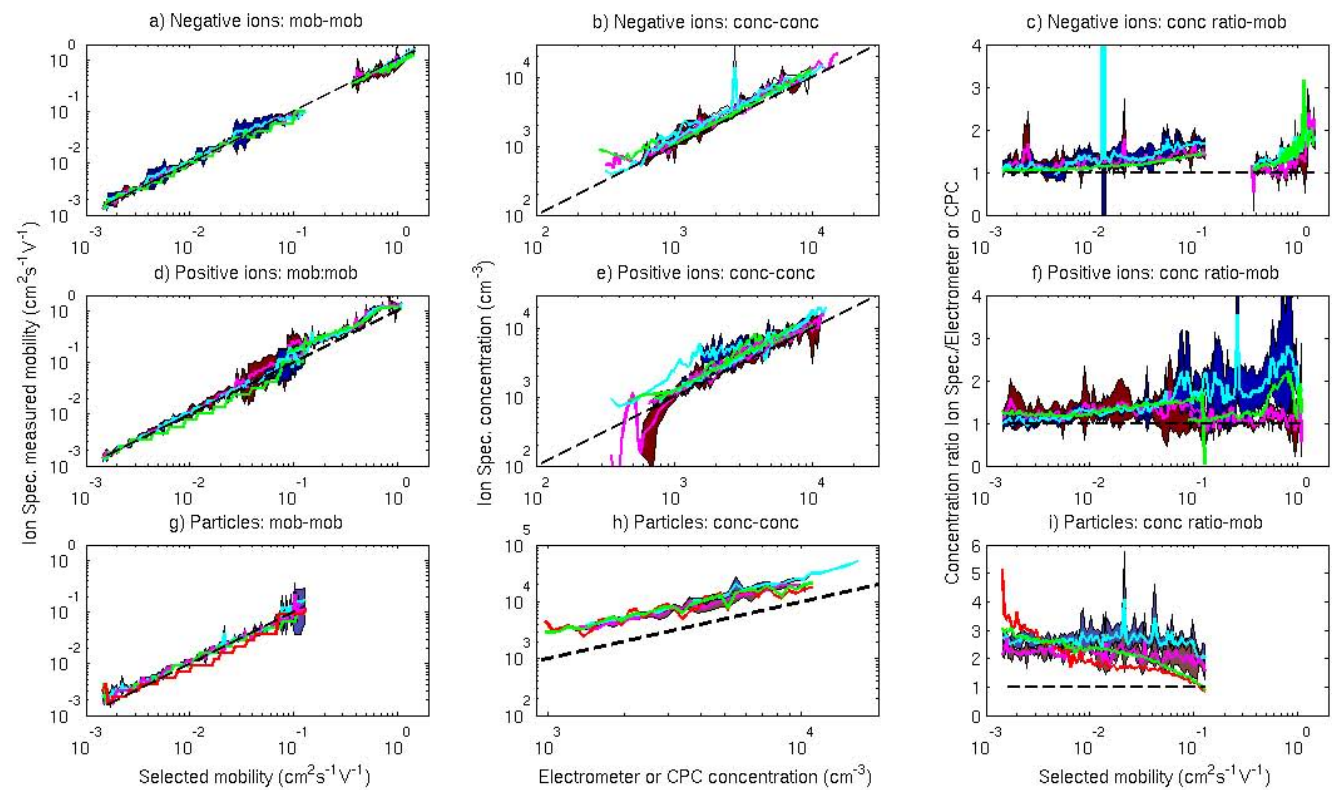

Fig. 4. Comparison of the ion spectrometers to reference instruments. (a), (b), (c): negative polarity; (d), (e), (f): positive polarity; (g), (h), (i): total particles (charged+neutral, NAISs only). Panels (a), (d) and (g) display the mobility measured by the ion spectrometers as a function of the mobility selected by the DMA. Panels (b), (e) and (h) display the total concentration measured by the ion spectrometers as a function of the concentration measured with reference instruments. Panels (c), (f) and (i) display the ratio of the ion spectrometer concentration to the concentration of the reference instrument as a function of the particle mobility. In panels (a) to (f), the AISs are represented by magenta lines and red filling (standard deviation between instruments), the NAISs by cyan lines and blue filling, and the ANAIS by a green line. The electrometer is the reference instrument in these two lines. In panels (g), (h) and (i), the total particles, cyan lines and blue fillings correspond to the negative DMAs of the ion spectrometers; magenta lines and red fillings correspond to the positive DMAs of the ion spectrometers. The green and red lines represent the negative and positive DMAs of the ANAIS, respectively. The reference instrument is the CPC in this line. The black dashed lines are the ideal values. All the points in this figure were obtained from calibration with silver particles.

In the particle measurement mode of the ion spectrometers, the peak mobility was detected accurately. In the case of the Airborne NAIS, the positive polarity DMA was underestimating the mobility while its negative polarity DMA was accurate. This can either be due to a temporary malfunction of the instrument (e.g. changes in flows) or to a difference between the positive and negative DMA data inversion. The large variation between the instruments for smaller particles is most probably due to corona ions being detected up to about $5 \mathrm{~nm}\left(0.08 \mathrm{~cm}^{2} \mathrm{~V}^{-1} \mathrm{~s}^{-1}\right)$, making the maximum of the measured mobility distribution difficult to find.

In the case of the particle measurement mode, the total concentration was calculated from $3.4 \mathrm{~nm}$ $\left(0.18 \mathrm{~cm}^{2} \mathrm{~V}^{-1} \mathrm{~s}^{-1}\right)$ instead of calculating the total concentration between 0.8 and $42 \mathrm{~nm}$. This was done in an attempt to avoid including most of the background corona ions (see Fig. 5). The smallest size selected with the Hauke DMA was $4 \mathrm{~nm}$, the DMA had a transmission width of $0.3 \mathrm{~nm}$. To avoid the corona ions completely, we changed the minimum size integrated in the total concentration from 3.4 to $5.6 \mathrm{~nm}$, but the overestimation of the concentration by the ion spectrometers remained. The concentration ratio with the reference instrument was still between 2 and 3 for first generation NAISs, although it decreased by about 0.2 compared to the ratio presented in ratio presented in Fig. 4i. This means that, even when avoiding corona ions, the NAISs seem to overestimate the concentration, especially in particle measurement mode. The concentration ratio does not vary much as a function of particle size for the NAISs. However, the Airborne NAIS overestimated the concentrations more significantly at bigger sizes than at smaller sizes. This is most likely due to a different inversion program provided by the manufacturer with the second generation models. The background concentration in particle mode is presented on the right side of Fig. 5. Most of the background is probably corona ions from the chargers. The median total background was $1.6 \times 10^{5} \mathrm{~cm}^{-3}$ for the negative DMA and $2.5 \times 10^{6} \mathrm{~cm}^{-3}$ for the positive DMA. When we applied the same minimum size of $3.4 \mathrm{~nm}$ to avoid corona ions, the background became much smaller with medians of $71.9 \mathrm{~cm}^{-3}$ and $86.5 \mathrm{~cm}^{-3}$ for the negative and positive DMA respectively. It is important to note that the background varies with the particle concentration. When there are particles in the sample air, part of the corona ions charge the particles and do not contribute to the background anymore. It is thus difficult to evaluate what fraction of the concentration is imputable to the background. 

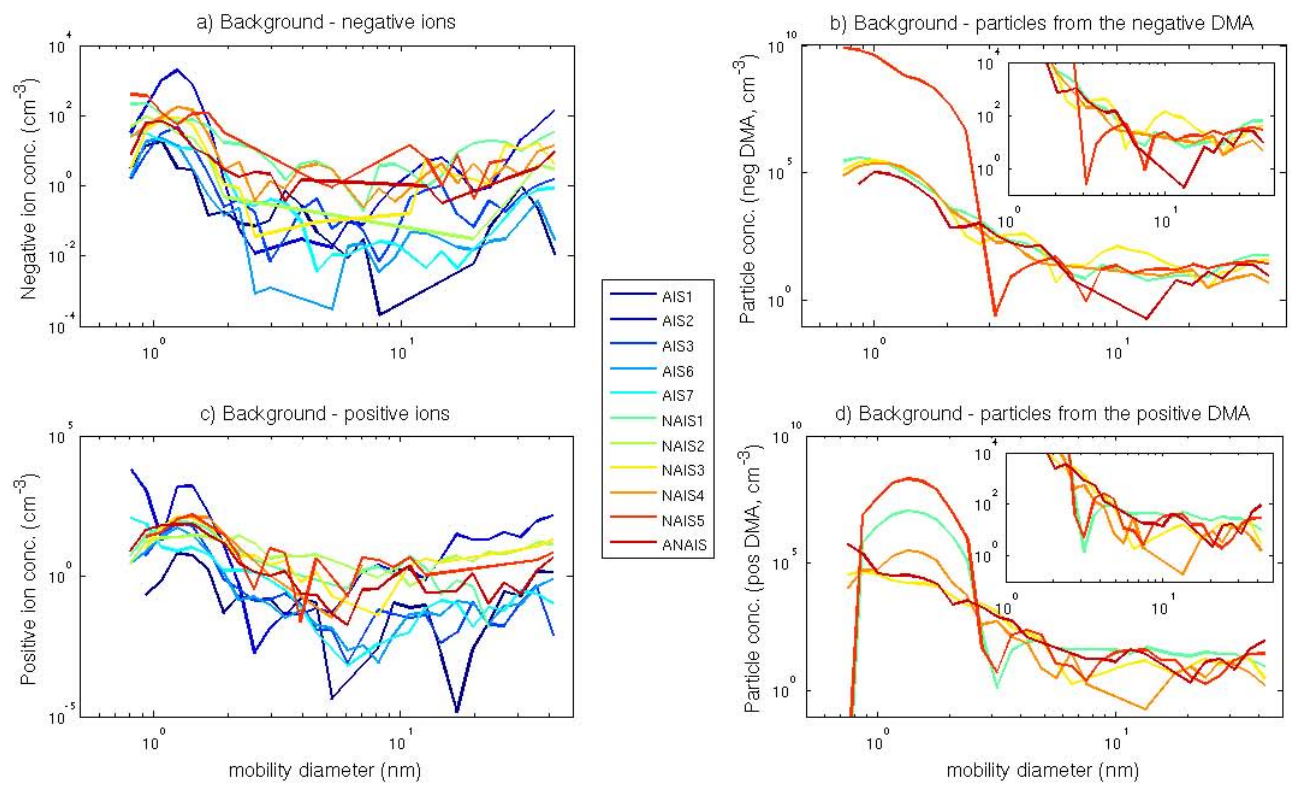

Fig. 5. The background concentrations is presented as a function of particle diameter. The total background concentration in ion measurement mode (a and c) was generally below $30 \mathrm{~cm}^{-3}$ for AISs and in the $30-150 \mathrm{~cm}^{-3}$ concentration range for NAISs. In particle measurement mode ( $\mathbf{b}$ and $\mathbf{d}$ ), the median total background concentration was $1.6 \times 10^{5} \mathrm{~cm}^{-3}$ and the median total background concentration above $3.4 \mathrm{~nm}$ was $86.5 \mathrm{~cm}^{-3}$. In these background measurements we used the Hauke DMA as a filter (by applying a zero voltage) to provide the ion spectrometers with particle-free air.

Concentration calibrations have shown that the efficiency of the ion spectrometers does not depend on the concentration, so that the ratio of the ion spectrometer concentration to a reference instrument concentration remains the same as a function of the concentration. This was observed both by detecting $15 \mathrm{~nm}$ particles at varying concentrations and by plotting the concentration ratios presented in Fig. 4 as a function of concentration.

\subsection{Intercomparison}

The intercomparison period lasted roughly 20 days between 31 May 2009 and 22 June 2009. During that time, the instruments were measuring in the intercomparison room as described in Sect. 3.4, unless they were being calibrated, cleaned, fixed, or malfunctioning. The days on which most of instruments were measuring uninterruptedly in the room were on 6-7 and 13-14 June 2009.

\subsubsection{Indoor and outdoor air measurements}

On the 6 June 2009, the instruments were measuring indoor air (Fig. 6a-d) and on the 7 June 2009, the instruments were measuring outdoor air through an opened door giving on a balcony on the highest floor of the building (Fig. 6e-h). Here, we present the median concentration and current for each size channel. In both cases, if the median was a negative value, the value was replaced by $1 \times 10^{-2} \mathrm{~cm}^{-3}$ for the concentrations and by $0.03 \mathrm{fA}$ for the currents in order to facili- tate visualization in logarithmic scale. The detection limit of the electrometers due to the noise is considered to be around $0.03 \mathrm{fA}$.

In the case of indoor air (Fig. 6a-d), the median concentration varied between about 0.01 and 10000 particles per $\mathrm{cm}^{3}$ per size channel (logarithmically spaced). The concentrations agree well from one instrument to another within the same instrument type, especially for negatively charged particles. However, once again, the NAISs display concentrations sometimes an order of magnitude bigger than the AISs depending on the particle diameter. This difference is also observed when looking at the raw electrometer signal on the right panels. The problem is bigger at small currents or concentration. In the case of outdoor air (Fig. 6e-h), the median concentration varied between about 1 and 2000 particles per $\mathrm{cm}^{3}$ per size channel. The instruments agree well with each other, although a difference of about an order of magnitude can be seen between instrument types at certain diameters. At concentrations approaching the detection limit, the difference can be explained by the difference in background concentrations. Again, the agreement is better for negatively charged particles than for positively charged particles. One can notice that the concentration of small particles is bigger in the indoor air, while the concentration of large particles $(>10 \mathrm{~nm})$ is bigger in outdoor air. This is probably due to coagulation of smaller particles onto the numerous larger particles found in outdoor air. 

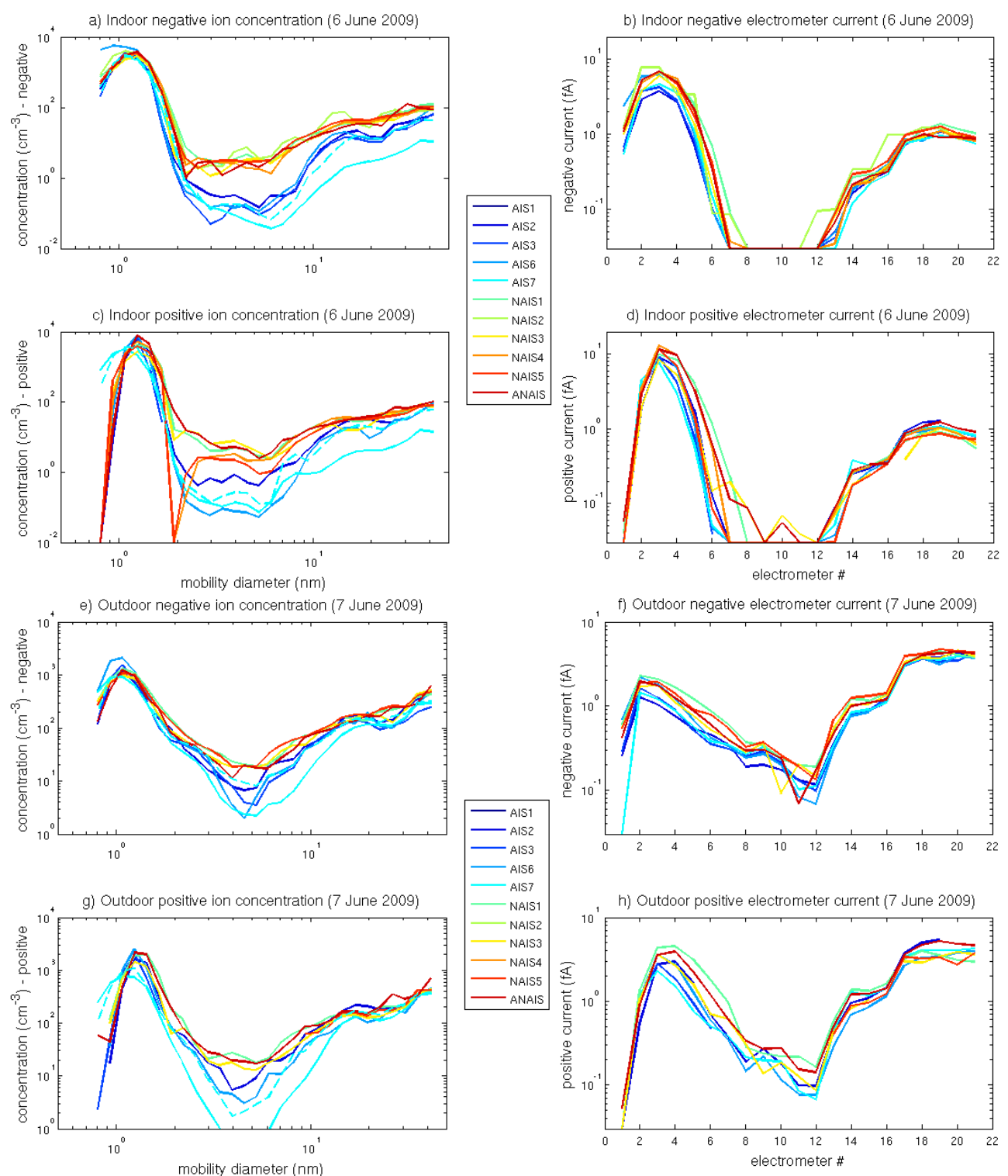

Fig. 6. Median concentration size distribution and electrometer current size distribution for indoor air (negative: (a), (b); positive: (c), (d), measured on 6 June 2009 and for outdoor air (negative: (e), (f); positive: (g), (h), measured on 7 June 2009. The AIS7 re-inverted concentrations are represented by the dashed line of the same color.

As can be seen from Fig. 6, the current of the AIS7 behaves like all other AISs, however, its concentrations are smaller than the other AISs is certain size ranges. The difference between the AIS7 and the others was caused by that the AIS7 was using different inverters, and had a much shorter measurement cycle. The AIS7 cycle was about 10 times shorter than the other AISs. This made noise levels more important in respect to the concentration, leading to the smaller concentrations. We re-inverted the currents using an inversion matrix that takes into account the shorter measurement cycle time. The new concentrations are presented in Figure 6 as dashed lines. One can see that the re-inverted out- put is much closer to the other AISs. Hence, we would like to point out the importance of using the appropriate inverters and upgrade the software in order to be comparable with other (N)AIS. This also shows that longer cycles are recommendable to allow better noise control leading to a better signal to noise ratio, and a better inversion of the currents.

\subsubsection{Mean diameter and concentration comparison}

The mean concentrations and diameters of ions and particles detected during the intercomparison workshop were calculated and are presented in Fig. 7. In general, all instruments showed similar concentrations and diameters, for both 

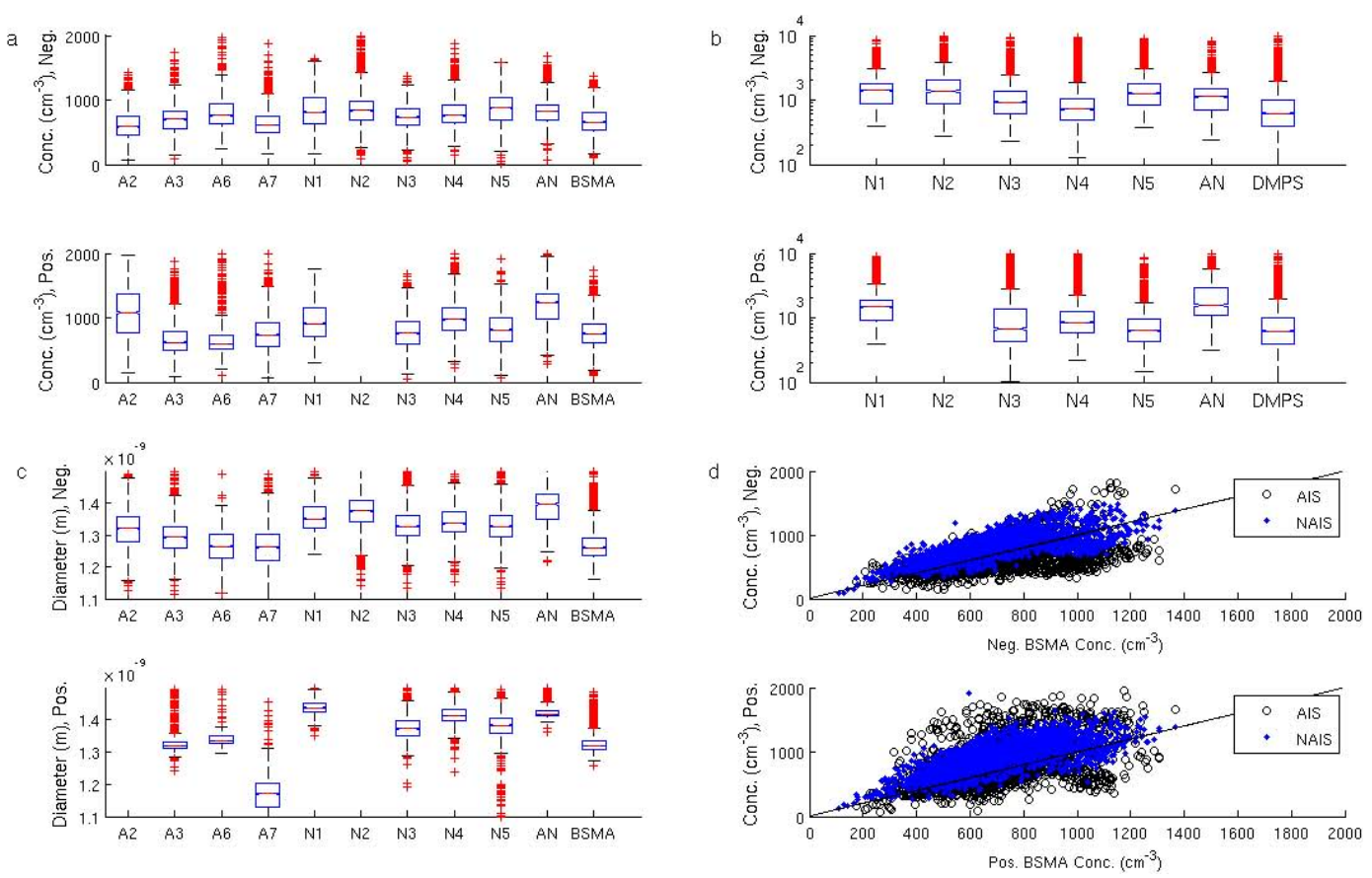

Fig. 7. Performance during the intercomparison period (7 June-25 June 2009). (a) Concentration of ions for AISs, NAISs and the BSMA (size range: 3-7 nm). (b) Concentration of particles for NAISs and the DMPS (size range: 10-40 nm). (c) Mean diameter for AISs, NAISs and the BSMA $(0.8-3 \mathrm{~nm})$. The red lines are the median value, the blue boxes are the 25-th and 75-th percentile, whiskers are 10-th and 90-th percentiles and red crosses are outliers. For readability purposes, the AISs are coded "A" and the NAISs, "N". The ANAIS is coded AN. (d) The total ion concentration of the ion spectrometers in the 3-7 nm size range is compared to the BSMA concentration. The AISs are represented by black circles and the NAISs by blue diamonds.

polarities, and also for neutral particles. However, in the case of negatively charged particles, measured with the ion measurement mode of the spectrometers, the AISs showed slightly smaller concentrations than the NAISs (Fig. 7a), consistent with the calibration results and the measurements of indoor and outdoor air. The BSMA, the reference instrument in this figure, agrees better with the AISs. For positively charged particle, the median concentrations varied more than for negatively charged particles. It is thus impossible to say whether the NAISs are overestimating the concentration for positively charged particles in this figure. As can be seen from Fig. 7d, the NAISs tend to measure higher concentrations than the AISs, at least for negatively charged particles at all concentrations. In general, the BSMA and the ion spectrometers agree well with each other.

The concentrations measured with the NAISs in the particle measurement mode can be compared to the DMPS as a reference instrument (Fig. 7b). The concentrations measured by the ion spectrometers were all in the same range. Once again, the negative analyzers agreed better with each other than the positive analyzers. For both polarities, the DMPS yielded smaller concentrations, suggesting that the NAISs may be overestimating the concentrations. The only differences between the AISs and NAISs are the extra charging modules found in the NAISs (causing a more turbulent flow) and a slightly different inversion process that takes into account the diffusional losses happening in these extra modules. The cause for the different concentrations, in this case, is most likely due to the differences in the flow turbulence and the data inversion process.

The size of small ions, smaller than $\sim 3 \mathrm{~nm}$, is influenced by air composition, temperature, pressure and sink due to aerosol particles (see e.g. Luts and Parts, 2002; Parts and Luts, 2004). The mean mobility or size of small ions has thus been reported in the literature (see Hirsikko et al., 2010 and references therein). During the intercomparison period, the diameter distribution of the $<3 \mathrm{~nm}$ particles varied from one instrument to another (Fig. 7c). The NAISs systematically had larger median diameters than the AISs, and the BSMA measured smaller diameters than the ion spectrometers in general. The median diameter of small ions varied between 1.25 and $1.45 \mathrm{~nm}$ with the exception of the AIS 7's positive mode and AIS 1's negative mode. Since the NAISs also detect different concentrations, and the diffusional losses are more important for smaller particles, it is probable that in the case of polydisperse particle distributions, the size distribution has been skewed. This difference in mobility diameter detection was not observed for monodisperse distributions (Fig. 3). Ehn et al. (2011) found that the size distribution from the BSMA compared well to the ion mass distribution 

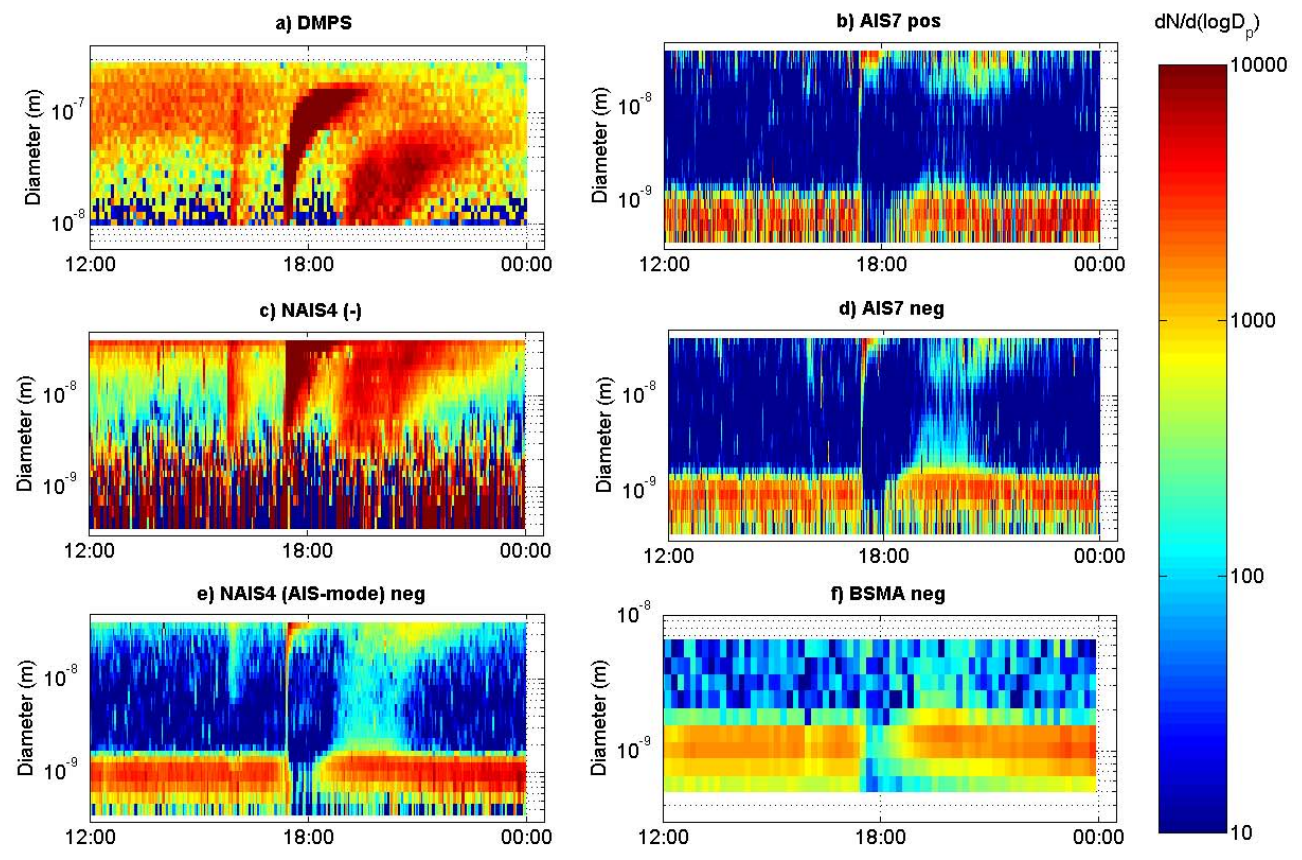

Fig. 8. Size distribution during the NPF event (12 June 2009) for a range of instruments. (a) DMPS, total concentration of aerosol particles, (b) AIS, positive air ions, (c) NAIS concentration of particles in particle operation mode (from the negative analyzer), (d) AIS negative air ions, (e) NAIS negative air ions, (f) BSMA negative air ions.

measured with the APi-TOF, whereas a shift towards larger sizes was observed when comparing AIS and APi-TOF. The median size of small ions is expected to differ according to their chemical composition.

\subsubsection{Measurements during a NPF event}

Three NPF events were provoked in the room during the intercomparison: on the 10, 12 and 14 June 2009. The NPF events were provoked by peeling citrus fruits in the middle of the room. The clearest event, with the most instruments monitoring it, was on 12 June 2009 and a sample of the results is presented in Fig. 8. What may look like a burst at ca. 15:30 is only due to briefly opening the door giving on the outside air. The fruits were peeled only at the start of the first burst at ca. 17:20. Secondary, weaker events started after the main one at 18:50 and 20:00. The core of the analysis will focus on the first secondary event, starting at 18:50.

The first event was very strong and fast, so that it was impossible to calculate the growth and formation rates accurately. After this event, the population of small ions was almost completely depleted. This is probably partly due to the high coagulation sink of the newly formed particles and partly to the activation of these small ions into new particles. The small ion population slowly rebuilt allowing the formation and growth of new particles (2nd and 3rd events). The concentration of small ions returned to normal levels once new particles had ceased to form, indicating the activation of small air ions during the event.
The charged fraction, which is the fraction of particles that are electrically charged, can be calculated for the NAIS data. It is presented for 12 June 2009 in Fig. 9. The charged fraction is the ratio of the concentration of charged particles (negatively + positively charged particles in the ion measurement mode) divided by the concentration of particles (NAIS particle measurement mode) for corresponding size ranges. Figure 9 shows the charged fraction of negatively (panels af) and positively (panels g-1) charged particles for 6 SIZE channels corresponding to 6 size channels of the Ion-DMPS. Since the NAISs provide two different measurements of the particle measurement mode (one for each DMA), the charged fraction was calculated for each DMA i.e. negative (positive) charged fraction $=$ negative (positive) ion concentration $\div$ particle concentration from the negative (positive) DMA. The charged fractions calculated from malfunctioning channel/polarity were removed from the figure.

The charged fractions measured with the NAISs were compared to the ones measured with the Ion-DMPS. The Ion-DMPS charged ratio was calculated as the ratio of the ambient mode concentration to the neutralized mode concentration (at steady-state charged fraction). The charged ratio was then multiplied by the steady state charging probability for the appropriate diameter (Wiedensohler, 1988) to get the charged fraction of the particles. The charged fraction derived from the Ion-DMPS data agrees with the range of charged fractions calculated with the different NAIS data. Based on calibration results, the charged fraction provided by the NAIS should be underestimated (because the particle 

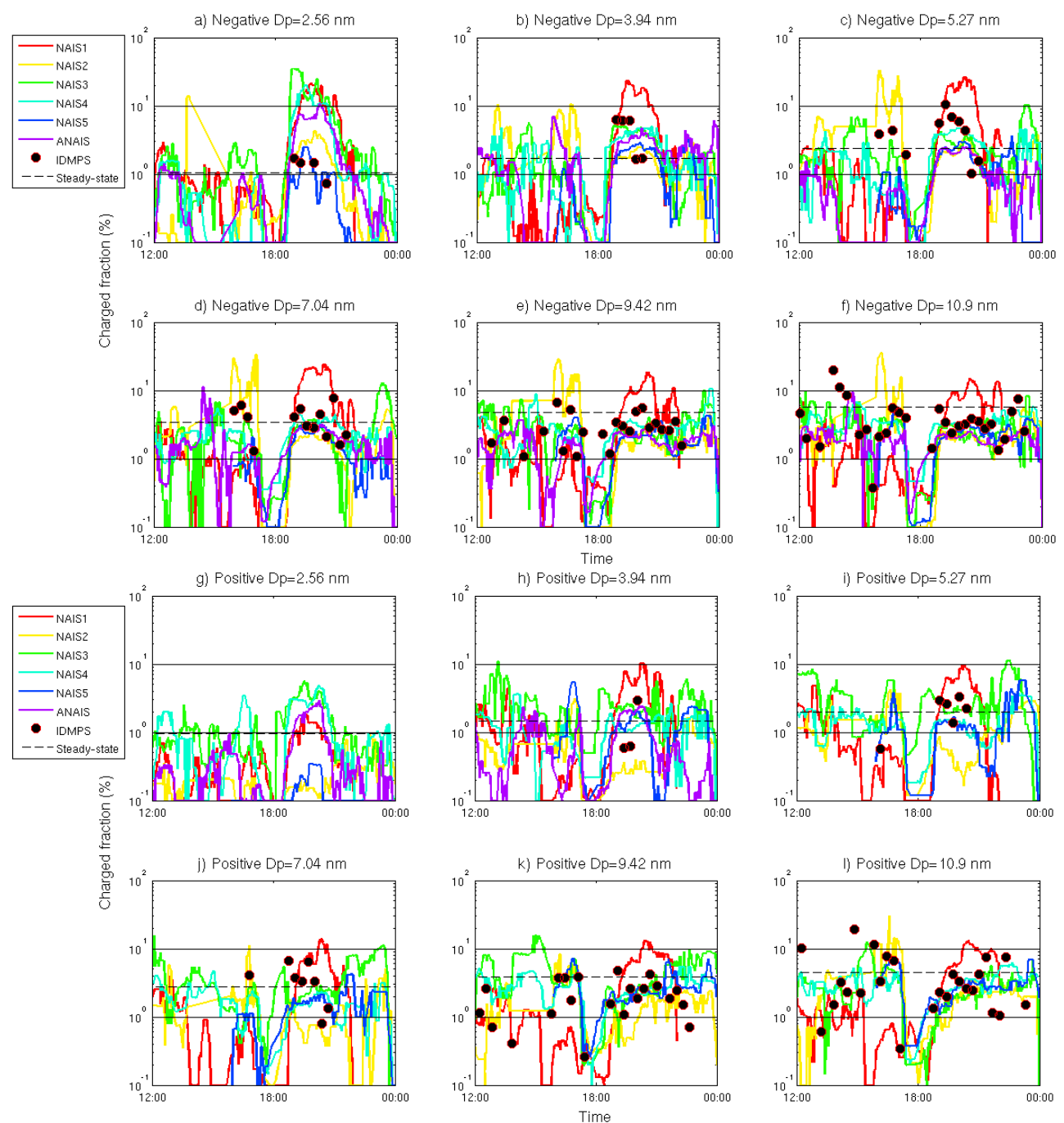

Fig. 9. Negative (a to $\mathbf{f}$ ) and positive ( $\mathbf{g}$ to $\mathbf{l}$ ) charged fraction (fraction of charged particles, in percents) at 6 different diameters per polarity as a function of time for all NAISs on 12 June 2009. The charged fraction retrieved by the Ion-DMPS is shown as black circles and the steady-state charged fraction is marked with a black dashed line.

concentration is overestimated, and the ion concentration is not overestimated as much). However, the charged fraction corresponds well to that of the Ion-DMPS. It is possible that the NAISs overestimate the total concentration in particle operation mode when the charged fraction of the aerosol sample is much bigger than the equilibrium of the unipolar charger (overcharged situations). The aerosol sample used in calibrations in the particle operation mode was neutralized by a bipolar charger so the sample should not have been in an overcharged state. In most field situations strong overcharging seems to be rare (see Manninen et al. (2010) and references therein), however the subject requires further investigation. It is not clear why the charged fraction corresponded so well to the Ion-DMPS.
Particle formation rates at $2 \mathrm{~nm}$ (Manninen et al., 2009b) were calculated from each instrument during the second event on 12 June. The formation rate is the rate at which new particles are formed and appear in a given size range, in our case, at $2 \mathrm{~nm}$ (Kulmala et al., 2007). Values are shown in Table 2 for all modes and instruments for which it was possible to get a value. One has to bear in mind that the formation and growth rates calculated with the method of using the methods of Manninen et al. (2009b) can be trusted within a factor 2 , and that using different methods may cause an even bigger difference. The new particle formation events were mostly driven by negatively charged particles as is often observed in other environments, in laboratory experiments and in quantum chemistry calculations (see e.g. Vana et al., 2006; Gagné 2010; Winkler et al., 2008; Kurtén et al., 2009). For that reason, it was impossible to calculate the formation rate in the 
Table 2. Analysis of the 2nd new particle formation event of 12 June 2009 (18:50) by different instruments and ions spectrometers (see Fig. 8 for details). $J_{2}$ is the formation rate at $2 \mathrm{~nm}$ for negative and positive ions, and for total particles. GR is the growth rate of particles negative or positive $(-/+)$ in different size ranges: $2-3,3-7$ and $7-20 \mathrm{~nm}$. The mean and standard deviation for the AISs and NAISs are shown in the last two rows.

\begin{tabular}{|c|c|c|c|c|c|c|c|c|c|}
\hline \multirow{3}{*}{$\begin{array}{l}\text { Instrument } \\
\text { AIS } 1\end{array}$} & \multicolumn{3}{|c|}{$J_{2}\left(\mathrm{~cm}^{-3} \mathrm{~s}^{-1}\right)$} & \multicolumn{6}{|c|}{$\mathrm{GR}\left(\mathrm{nm} \mathrm{h}^{-1}\right)$} \\
\hline & \multirow{2}{*}{$\frac{\text { negative }}{-}$} & \multirow{2}{*}{$\begin{array}{l}\text { positive } \\
-\end{array}$} & \multirow{2}{*}{$\begin{array}{l}\text { particle } \\
-\end{array}$} & \multicolumn{2}{|c|}{$2-3 \mathrm{~nm}(-/+)$} & \multicolumn{2}{|c|}{$3-7 \mathrm{~nm}(-/+)$} & \multicolumn{2}{|c|}{$7-20 \mathrm{~nm}(-/+)$} \\
\hline & & & & - & - & - & - & - & - \\
\hline AIS 2 & 0.13 & - & - & 12.3 & - & 24.5 & - & 34.9 & - \\
\hline AIS 3 & 0.18 & - & - & 12.8 & - & 22.6 & - & 33.8 & - \\
\hline AIS 6 & - & - & - & - & - & - & - & - & - \\
\hline AIS 7 & 0.15 & - & - & 16.3 & - & 33.8 & - & 37.7 & - \\
\hline NAIS 1 & 0.21 & 0.08 & 2.2 (weak) & 15.2 & 13.3 & 21.4 & 23.4 & 39.6 & 39.3 \\
\hline NAIS 2 & 0.23 & - & - & 9.6 & - & 27.5 & - & 37.1 & - \\
\hline NAIS 3 & 0.20 & - & 3.9 & 11.2 & - & 27.1 & - & 34.6 & - \\
\hline NAIS 4 & 0.21 & 0.07 & 1.6 (weak) & 13.7 & 10.8 & 22.7 & 19.1 & 37.3 & 36.2 \\
\hline NAIS 5 & 0.24 & 0.09 & 1.3 (weak) & 15.8 & 12.2 & 22.9 & 25.1 & 34.9 & 38.9 \\
\hline A-NAIS & 0.20 & 0.08 & 4.7 & 16.2 & 13.2 & 25.3 & 22.0 & 38.1 & - \\
\hline DMPS & - & - & 1.1 & - & - & - & - & $37(1$ & $-20 \mathrm{~nm})$ \\
\hline BSMA & 0.27 & - & - & 11.4 & - & 23.0 & - & - & \\
\hline $\begin{array}{l}\text { AIS (mean and } \\
\text { st. dev.) }\end{array}$ & $0.15 \pm 0.03$ & - & - & $13.8 \pm 2.2$ & - & $27.0 \pm 7.0$ & - & 35.5 & 2.0 \\
\hline $\begin{array}{l}\text { NAIS (mean } \\
\text { and st. dev.) }\end{array}$ & $0.22 \pm 0.02$ & $0.08 \pm 0.01$ & $2.7 \pm 1.5$ & $13.6 \pm 2.7$ & $12.4 \pm 1.2$ & $24.5 \pm 2.5$ & $22.4 \pm 2.5$ & 38.1 & 1.7 \\
\hline
\end{tabular}

positive mode for all AISs and some NAISs. The formation rates calculated from the AISs' negative mode were smaller than those calculated from the NAISs' same mode. This is consistent with the finding that NAISs seem to overestimate the ion concentration, especially at small diameters where the formation rates were calculated. The formation rate of ions calculated based on the BSMA was higher than those of the other ion spectrometers, closer to the NAISs than the AISs. During the intercomparison, the BSMA agreed better with the AISs because small ions $(<2 \mathrm{~nm})$ were dominating the size distribution. However, during the NPF event, the concentration of small ions decreased and the concentration of larger particles increased. The BSMA agrees better with the NAISs in the larger size range.

The formation rate in the particle mode was calculated in the case of NAISs using the same method as for ions. The formation rate of particles at $2 \mathrm{~nm}$ was also calculated from the DMPS. Due to the measurement range of the DMPS, the formation rate was first calculated at $10 \mathrm{~nm}$ and then scaled back to $2 \mathrm{~nm}$ using the formula described by Kerminen and Kulmala (2002) to be comparable to those calculated with the ion spectrometers. The formation rate $J_{2}$ of ions was found to be around $0.1-0.3\left(\mathrm{~cm}^{-3} \mathrm{~s}^{-1}\right)$. The BSMA gave the highest rate $\left(0.27 \mathrm{~cm}^{-3} \mathrm{~s}^{-1}\right)$ while the AISs and the NAISs gave an average of $0.15 \mathrm{~cm}^{-3} \mathrm{~s}^{-1}$ and $0.22 \mathrm{~cm}^{-3} \mathrm{~s}^{-1}$ respectively. The difference between the AISs and the NAISs is not a surprise since the NAISs seem to have a tendency to overestimate the concentrations. In particle mode, the DMPS gave a formation rate of $1.1 \mathrm{~cm}^{-3} \mathrm{~s}^{-1}$ while the NAIS average was
$2.7 \mathrm{~cm}^{-3} \mathrm{~s}^{-1}$, again this is not too surprising given the results given in Figs. $4 \mathrm{~g}-\mathrm{i}$ and $7 \mathrm{~b}$.

Also, the growth rates of particles were calculated for the AISs, NAISs DMPS and BSMA. The growth rate is the rate at which particles in a given size range grow. The results are presented in Table 2. Due to the small concentrations in the positive mode, it was impossible to calculate them for all the instruments. The growth rates were calculated in 3 different size ranges: $2-3 \mathrm{~nm}, 3-7 \mathrm{~nm}$ and $7-20 \mathrm{~nm}$. As observed before, the growth is slower at small diameters and faster at bigger diameters (Hirsikko et al., 2007; Yli-Juuti et al., 2009). The AISs gave an average growth rate of 13.8 , 27.0 and $35.5 \mathrm{~nm} \mathrm{~h}^{-1}$ in each size range, respectively. The NAISs, on the other hand showed growth rates of 13.6, 24.5, $38.1 \mathrm{~nm} \mathrm{~h}^{-1}$ for the negative polarity and slightly smaller values for the positive polarity. The BSMA yielded a growth rate of $11.4 \mathrm{~nm} \mathrm{~h}^{-1}$ in the $2-3 \mathrm{~nm}$ size range and 23.0 in the 3-7 $\mathrm{nm}$ range. The DMPS gave a growth rate of $37 \mathrm{~nm} \mathrm{~h}^{-1}$ in the 10-20 nm size range. No clear difference between the AISs and the NAISs was observed in the determination of the growth rate. This result can be explained by an accurate detection of the mobility for both types of instruments as shown in Figs. 3 and 4. 


\section{Conclusions}

In this work, we inspected 11 ion spectrometers that had been deployed in field measurements during the EUCAARI project in 2007-2009. Three types of ion spectrometers were characterized and compared: 5 AISs, 5 NAISs and one second generation NAIS that is called an Airborne NAIS (ANAIS). We evaluated the response of the instruments regarding mobility (particle size) and concentration using mobility standards and silver particles in two experimental setups covering a size range between roughly 1 and $40 \mathrm{~nm}$ (the measurements performed are resumed in Table 1). We also had all the ion spectrometers and three reference instruments (BSMA, DMPS, ion-DMPS) measuring ambient indoor and outdoor air during the workshop, and compared their response. In addition, we provoked a new particle formation event in the room air that was monitored by all ion spectrometers side by side with the reference instruments. The formation and growth rates as well as the charged fraction were calculated and compared for all ion spectrometers and relevant reference instruments.

Based on the results presented in this paper, we present a number of results to keep in mind while performing analysis of air ion spectrometer data and evaluating results from different instruments:

1. The mobility detection can be trusted for AISs and NAISs, provided that the instrument is clean and the flows are not obstructed.

2. The growth rates calculated from the ion spectrometer data are reliable (as a consequence of conclusion 1 and the analysis of a NPF event).

3. The concentration can vary from one individual instrument to the other by up to $10 \%$ within the same instrument type.

4. In ion measurement mode, the NAISs give higher concentrations than the AISs, the AISs agreed better with the BSMA.

5. The NAISs can overestimate the concentration by a factor of 2-3 in particle measurement mode (based on calibration results and comparison with a DMPS).

6. The formation rates vary from one individual instrument to the other (based on conclusion 3; it is also important to note that formation rates can be trusted within a factor 2 with the method described by Manninen et al., 2009).

7. The formation rates calculated from NAISs are higher than those calculated from AISs in ion measurement mode. However, the BSMA agreed better with the NAISs.

8. The formation rates of particles calculated from NAISs (in particle measurement mode) are higher than the reference instrument (based on conclusion 5 and on the analysis of a NPF event where it was compared to a DMPS).

9. The charged fraction calculated from NAISs is still considered unreliable even though it compared well with the reference instrument in this work (based on the analysis of a NPF event where it was compared to an IonDMPS).

The ion spectrometers proved to be good mobility detectors in ion measurement mode (Fig. 3). In particle measurement mode, some NAIS models had better accuracy than others (Fig. 4). The concentration measurements were in good agreement with the reference instruments for AIS models (Figs. 4 and 7). The ion spectrometers seemed to overestimate the concentrations as the particle size decreases. This can be partly explained by uncertainties with the different experimental setups, but a general tendency remains (Fig. 4). The NAIS models also detected the concentration well, but slightly overestimated the concentration compared to the AISs and the reference instruments. This was observed both in calibration measurements (Fig. 4) and in ambient measurements (Figs. 6 and 7a). Moreover, the NAISs had bigger background concentrations than the AISs (Fig. 5). In particle measurement mode, the NAISs overestimated the concentration by a factor 2 to 3 , again both in calibration (Fig. 4) and in ambient measurements (Fig. 7b). The overestimation in the particle measurement mode seemed to be independent of the mobility for all NAISs except for the Airborne NAIS (Fig. 4). This was attributed to the different inversion process that the ANAIS and second generation NAISs use. At smaller particle sizes, the concentration of the ANAIS data seemed to be closer to the reference values, whereas the concentration was overestimated at bigger particle sizes.

A new particle formation event was detected by all the ion spectrometers as well as a BSMA, a DMPS and an Ion-DMPS. The formation rate $J_{2}$ of ions was found to be around $0.1-0.3\left(\mathrm{~cm}^{-3} \mathrm{~s}^{-1}\right)$. The BSMA gave a rate of $0.27 \mathrm{~cm}^{-3} \mathrm{~s}^{-1}$, the highest rate of all instruments. The AISs gave an average of $0.15 \mathrm{~cm}^{-3} \mathrm{~s}^{-1}$ and the NAISs (including the ANAIS) an average of $0.22 \mathrm{~cm}^{-3} \mathrm{~s}^{-1}$. It is not surprising to get higher formation rates from the NAISs than from the AISs given that the NAISs show higher concentrations than the AISs. In particle measurement mode, the formation rate at $2 \mathrm{~nm}$ scaled back from the DMPS measurements was $1.1 \mathrm{~cm}^{-3} \mathrm{~s}^{-1}$ while the average for NAISs was $2.7 \mathrm{~cm}^{-3} \mathrm{~s}^{-1}$. We thus recommend that this result be kept in mind when calculating formation rates from an NAIS, especially if compared with an AIS or with a DMPS/SMPS system.

The differences between the calculated formation rates may also have an effect on the ion-induced fraction, which has been previously calculated as the ratio of the ion formation rate to the particle formation rate (see e.g. Manninen et al., 2009b, 2010). Our results in Fig. 4 suggest that the overestimation is more important in particle measurement mode 
than in ion measurement mode. Thus the ratio of the ion and particle formation rates, representing a part of the ioninduced fraction calculated from NAIS data, may be slightly underestimated (this does not affect the recombination part of the calculations). However, the charged fraction itself does not seem to be affected too greatly by this difference in formation rates (Fig. 9), probably because the charged fraction was not too high. The charged fraction calculated with the Ion-DMPS data was generally slightly higher than the one calculated with the NAISs data. The Ion-DMPS and the ion spectrometers yielded a similar behavior for the charged fraction, especially at larger diameters where the Ion-DMPS is more reliable, suggesting that the charged fraction obtained from the NAISs is a good estimation, at least at larger sizes $(>9 \mathrm{~nm})$.

The growth rates, presented in Table 2, were similar for all the ion spectrometers, regardless of whether they were AISs or NAISs, and agreed well with the reference instruments. This is a direct result of the high performance of the instruments regarding mobility detection. The growth rates were about $14,25,35 \mathrm{~nm} \mathrm{~h}^{-1}$ in the $2-3,3-7,7-40 \mathrm{~nm}$ size range, respectively.

The ion spectrometers evaluated in this paper performed well, despite having spent a year in varying weather conditions. They proved to be reliable and enduring instruments, although they need to be cleaned regularly to insure the quality of the data. Some systematic differences between the AISs and NAISs were observed, as well as minor differences between the first and second generation of NAISs. The reasons behind the overestimation of the concentration by NAISs did not become clear during the calibration workshop. Additionally, the inversion processes may need some improvements, especially in particle measurement mode. A measurement-based data inversion could be a replacement solution to the present theory-based data inversion of the air ion spectrometers.

Acknowledgements. Jani Hakala, Jyri Mikkilä and Joonas Vanhanen are acknowledged for their help in various tasks throughout the workshop. Ella-Maria Kyrö and Anna Frey are acknowledged for their help in preparing the instruments for calibration. This research was supported by the Academy of Finland Center of Excellence program (project number 1118615), the European Commission 6th Framework program project EUCAARI, contract no 036833-2 (EUCAARI) and the Estonian Science Foundation, grant number 8342. The work of A. Franchin and S. Schobesberger was supported by the European Commission under the 7th Framework Programme (grant agreement number 215072: Marie Curie Initial Training Network, CLOUD-ITN).

Edited by: J. Curtius

\section{References}

Aalto, P., Hämeri, K., Becker, E., Weber, R., Salm, J., Mäkelä, J. M., Hoell, C., O’Dowd, C. D., Karlsson, H., Hansson, H.-C., Väkevä, M., Koponen, I. K., Buzorius, G., and Kulmala, M.: Physical characterization of aerosol particles during nucleation events, Tellus, 53B, 344-358, 2001

Andronache, C., Grönholm, T., Laakso, L., Phillips, V., and Venäläinen, A.: Scavenging of ultrafine particles by rainfall at a boreal site: observations and model estimations, Atmos. Chem. Phys., 6, 4739-4754, doi:10.5194/acp-6-4739-2006, 2006.

Asmi, E., Sipilä, M., Manninen, H. E., Vanhanen, J., Lehtipalo, K., Gagné, S., Neitola, K., Mirme, A., Mirme, S., Tamm, E., Uin, J., Komsaare, K., Attoui, M., and Kulmala, M.: Results of the first air ion spectrometer calibration and intercomparison workshop, Atmos. Chem. Phys., 9, 141-154, doi:10.5194/acp-9-141-2009, 2009.

Duplissy, J., Enghoff, M. B., Aplin, K. L., Arnold, F., Aufmhoff, H., Avngaard, M., Baltensperger, U., Bondo, T., Bingham, R., Carslaw, K., Curtius, J., David, A., Fastrup, B., Gagné, S., Hahn, F., Harrison, R. G., Kellett, B., Kirkby, J., Kulmala, M., Laakso, L., Laaksonen, A., Lillestol, E., Lockwood, M., Mäkelä, J., Makhmutov, V., Marsh, N. D., Nieminen, T., Onnela, A., Pedersen, E., Pedersen, J. O. P., Polny, J., Reichl, U., Seinfeld, J. H., Sipilä, M., Stozhkov, Y., Stratmann, F., Svensmark, H., Svensmark, J., Veenhof, R., Viisanen, Y., Wagner, P. E., Wehrle, G., Weingartner, E., Wex, H., Wilhelmsson, M., and Winkler, P. M.: Results from the CERN pilot CLOUD experiment, Atmos. Chem. Phys., 10, 1635-1647, doi:10.5194/acp-10-16352010, 2010.

Eichler, T.: A Differential Mobility analyzer for ions and nanoparticles: Laminar flow at high Reynolds numbers, Senior Graduation Thesis presented to Fachhochschule Offenburg, Germany, May 1997.

Ehn, M., Junninen, H., Schobesberger, S., Manninen, H., Franchin, A., Sipilä, M., Petäjä, T., Kerminen, V.-M., Tammet, H., Mirme, A., Mirme, S., Hõrrak, U., Kulmala, M., and Worsnop, D. R.: An instrumental comparison of mobility and mass measurements of atmospheric small ions, Aerosol Sci. Technol., 45, 522-532, 2011.

Fuchs, N. A. and Sutugin, A. G.: Highly dispersed aerosols, Vol H of In Topics in Current Aerosol Research, Pergamon Press, New York, 19439, 1971.

Gagné, S., Nieminen, T., Kurtén, T., Manninen, H. E., Petäjä, T., Laakso, L., Kerminen, V.-M., Boy, M., and Kulmala, M.: Factors influencing the contribution of ion-induced nucleation in a boreal forest, Finland, Atmos. Chem. Phys., 10, 3743-3757, doi:10.5194/acp-10-3743-2010, 2010.

Harrison, R. G. and Carslaw, K. S.: Ion-aerosol-cloud processes in the lower atmosphere, Reviews of Geophysics, 41, 1012, 2003.

Herrmann,W., Eichler, T., Bernardo, N., and Fernández de la Mora, J.: Turbulent transition arises at Re 35000 in a short Viennatype DMA with a large laminarizing inlet, Abstract to the annual conference of the AAAR, St. Louis, MO, 6-10 October, 2000.

Hirsikko, A., Laakso, L., Hõrrak, U., Aalto, P.P., Kerminen, V.M., and Kulmala, M.: Annual and size dependent variation of growth rates and ion concentrations in boreal forest, Boreal Environ. Res., 10, 357-369, 2005.

Hirsikko, A., Yli-Juuti, T., Nieminen, T., Vartiainen, E., Laakso, L., Hussein, T., and Kulmala, M.: Indoor and outdoor air ion and 
aerosol particles in the urban atmosphere of Helsinki: characteristics, sources and formation, Boreal Environ. Res., 12, 295-310, 2007.

Hirsikko, A., Nieminen, T., Gagné, S., Lehtipalo, K., Manninen, H. E., Ehn, M., Hrrak, U., Kerminen, V.-M., Laakso, L., McMurry, P. H., Mirme, A., Mirme, S., Petäjä, T., Tammet, H., Vakkari, V., Vana, M., and Kulmala, M.: Atmospheric ions and nucleation: a review of observations, Atmos. Chem. Phys., 11, 767798, doi:10.5194/acp-11-767-2011, 2011.

Jokinen, V. and Mäkelä, J.: Closed loop arrangement with critical orifice for DMA sheath/excess flow system, J. Aerosol Sci., 28, 643-648, 1996.

de Juan, L. and Fernández de la Mora, J.: Size analysis of nanoparticles and ions: Running a Vienna DMA of near optimal length at Reynolds numbers up to 5000, J. Aerosol Sci., 29, 617-626, 1998.

Kerminen, V.-M. and Kulmala, M.: Analytical formulae connecting the "real" and the "apparent" nucleation rate and the nuclei number concentration for atmospheric nucleation events, J. Aerosol Sci., 33, 609-622, 2002.

Kerminen, V.-M., Petäjä, T., Manninen, H. E., Paasonen, P., Nieminen, T., Sipilä, M., Junninen, H., Ehn, M., Gagné, S., Laakso, L., Riipinen, I., Vehkamäki, H., Kurten, T., Ortega, I. K., Dal Maso, M., Brus, D., Hyvärinen, A., Lihavainen, H., Leppä, J., Lehtinen, K. E. J., Mirme, A., Mirme, S., Hõrrak, U., Berndt, T., Stratmann, F., Birmili, W., Wiedensohler, A., Metzger, A., Dommen, J., Baltensperger, U., Kiendler-Scharr, A., Mentel, T. F., Wildt, J., Winkler, P. M., Wagner, P. E., Petzold, A., Minikin, A., Plass-Dülmer, C., Pschl, U., Laaksonen, A., and Kulmala, M.: Atmospheric nucleation: highlights of the EUCAARI project and future directions, Atmos. Chem. Phys., 10, 10829-10848, doi:10.5194/acp-10-10829-2010, 2010.

Kulmala, M., Laakso, L., Lehtinen, K. E. J., Riipinen, I., Dal Maso, M., Anttila, T., Kerminen, V.-M., Hõrrak, U., Vana, M., and Tammet, H.: Initial steps of aerosol growth, Atmos. Chem. Phys., 4, 2553-2560, doi:10.5194/acp-4-2553-2004, 2004a.

Kulmala, M., Vehkamäki, H., Petäjä, T., Dal Maso, M., Lauri, A., Kerminen, V.-M., Birmili, W., and McMurry, P. H.: Formation and growth of ultrafine atmospheric particles: a review of observations, J. Aerosol Sci., 35, 143-176, 2004b.

Kulmala, M., Riipinen, I., Sipilä, M., Manninen, H., Petäjä, T., Junninen H., Dal Maso, M., Mordas, G., Mirme, A., Vana, M., Hirsikko, A., Laakso, L., Harrison, R. M., Hanson, I., Leung, C., Lehtinen, K. E. J., and Kerminen, V.-M.: Toward Direct Measurement of Atmospheric Nucleation, Science, 318, 89-92, doi:10.1126/science.1144124, 2007.

Kulmala, M., Asmi, A., Lappalainen, H. K., Carslaw, K. S., Pöschl, U., Baltensperger, U., Hov, Ø., Brenquier, J.-L., Pandis, S. N., Facchini, M. C., Hansson, H.-C., Wiedensohler, A., and O'Dowd, C. D.: Introduction: European Integrated Project on Aerosol Cloud Climate and Air Quality interactions (EUCAARI) - integrating aerosol research from nano to global scales, Atmos. Chem. Phys., 9, 2825-2841, doi:10.5194/acp-9-2825-2009, 2009.

Kurtén, T., Ortega, I. K., and Vehkamäki, H.: The sign preference in sulfuric acid nucleation, Journal of Molecular Structure: THEOCHEM, 901, 169-173, 2009.

Laakso, L., Mäkelä, J. M., Pirjola, L., and Kulmala, M.,: Model studies on ion-induced nucleation in the atmosphere, J. Geophys.
Res.-Atmos., 107, 4427, doi:10.1029/2002JD002140, 2002.

Laakso, L., Gagné, S., Petäjä, T., Hirsikko, A., Aalto, P. P., Kulmala, M., and Kerminen, V.-M.: Detecting charging state of ultra-fine particles: instrumental development and ambient measurements, Atmos. Chem. Phys., 7, 1333-1345, doi:10.5194/acp-7-13332007, 2007.

Lohmann, U. and Feichter, J.: Global indirect aerosol effects: a review, Atmos. Chem. Phys., 5, 715-737, doi:10.5194/acp-5-7152005, 2005.

Lovejoy, E. R., Curtius, J., and Froyd, K. D.: Atmospheric ioninduced nucleation of sulfuric acid and water, J. Geophys. Res., 109, D08204, doi:10.1029/2003JD004460, 2004.

Luts, A. and Parts, T.-E.: Evolution of negative small air ions at two different temperatures, J. Atmos. Sol.-Terr. Phys., 64, 763-774, 2002.

Manninen, H. E., Petäjä, T., Asmi, E., Riipinen, I., Nieminen, T., Mikkilä, J., Hõrrak, U., Mirme, A., Mirme, S., Laakso, L., Kerminen, V.-M., and Kulmala, M.: Long-term field measurements of charged and neutral clusters using Neutral cluster and Air Ion Spectrometer (NAIS), Boreal Environ. Res., 14, 591-605, 2009a.

Manninen, H. E., Nieminen, T., Riipinen, I., Yli-Juuti, T., Gagné, S., Asmi, E., Aalto, P. P., Petäjä, T., Kerminen, V.-M., and Kulmala, M.: Charged and total particle formation and growth rates during EUCAARI 2007 campaign in Hyytiälä, Atmos. Chem. Phys., 9, 4077-4089, doi:10.5194/acp-9-4077-2009, 2009b.

Manninen, H. E., Nieminen, T., Asmi, E., Gagné, S., Hkkinen, S., Lehtipalo, K., Aalto, P., Vana, M., Mirme, A., Mirme, S., Hõrrak, U., Plass-Dülmer, C., Stange, G., Kiss, G., Hoffer, A., Törő, N., Moerman, M., Henzing, B., de Leeuw, G., Brinkenberg, M., Kouvarakis, G. N., Bougiatioti, A., Mihalopoulos, N., O'Dowd, C., Ceburnis, D., Arneth, A., Svenningsson, B., Swietlicki, E., Tarozzi, L., Decesari, S., Facchini, M. C., Birmili, W., Sonntag, A., Wiedensohler, A., Boulon, J., Sellegri, K., Laj, P., Gysel, M., Bukowiecki, N., Weingartner, E., Wehrle, G., Laaksonen, A., Hamed, A., Joutsensaari, J., Petäjä, T., Kerminen, V.-M., and Kulmala, M.: EUCAARI ion spectrometer measurements at 12 European sites - analysis of new particle formation events, Atmos. Chem. Phys., 10, 7907-7927, doi:10.5194/acp-10-79072010, 2010.

Matisen, R., Miller, F., Tammet, H. and Salm, J.: Air ion counters and spectrometers designed in Tartu University, Acta et Comm. Univ. Tartuensis, 947, 60-67, 1992.

Mirme, A., Tamm, E., Mordas, G., Vana, M., Uin, J., Mirme, S., Bernotas, T., Laakso, L., Hirsikko, A., and Kulmala, M.: A widerange multi-channel Air Ion Spectrometer, Boreal Environ. Res., 12, 247-264, 2007.

Mirme, S., Mirme, A., Minikin, A., Petzold, A., Hõrrak, U., Kerminen, V.-M., and Kulmala, M.: Atmospheric sub-3 nm particles at high altitudes, Atmos. Chem. Phys., 10, 437-451, doi:10.5194/acp-10-437-2010, 2010.

Myhre, G., Berglen, T. F., Johnsrud, M., Hoyle, C. R., Berntsen, T. K., Christopher, S. A., Fahey, D. W., Isaksen, I. S. A., Jones, T. A., Kahn, R. A., Loeb, N., Quinn, P., Remer, L., Schwarz, J. P., and Yttri, K. E.: Modelled radiative forcing of the direct aerosol effect with multi-observation evaluation, Atmos. Chem. Phys., 9, 1365-1392, doi:10.5194/acp-9-1365-2009, 2009.

Mäkelä, J. M., Riihelä, M., Ukkonen, A., Jokinen, V., and Keskinen, J.: Comparison of mobility equivalent diameter with KelvinThomson diameter using ion mobility data, J. Chem. Phys., 105, 
1562-1571, 1996.

Parts, T.-E. and Luts, A.: Observed and simulated effects of certain pollutants on small air ion spectra: I. Positive ions, Atmos. Environ., 38(9), 1283-1289, 2004.

Stevens, B. and Feingold, G.: Untangling aerosol effects on clouds and precipitation in a buffered system, Nature, 461, 607-613, 2009.

Stolzenburg, M. R. and McMurry, P. H.: An Ultrafine Aerosol Condensation Nucleus Counter, Aerosol Sci. Technol., 14, 48-65, 1991.

Tammet, H.: Continuous scanning of the mobility and size distribution of charged clusters and nanometer particles in atmospheric air and the Balanced Scanning Mobility Analyzer BSMA, Atmos. Res., 82, 523-535, 2006.

Twomey, S.: Aerosols, clouds and radiation, Atmos. Environ., 25A, 2435-2442, 1991.

Ude, S. and Fernández de la Mora, J.: Molecular monodisperse mobility and mass standards from electrosprays of tetra-alkyl ammonium halides, J. Aerosol Sci., 36, 1224-1237, 2005.

Vana, M., Tamm, E., Hõrrak, U., Mirme, A., Tammet, H., Laakso, L., Aalto, P., and Kulmala, M.: Charging state of atmospheric nanoparticles during the nucleation burst events, Atmos. Res., 82, 536-546, 2006.
Vartiainen, E., Kulmala, M., Ehn, M., Hirsikko, A., Junninen, H., Petäjä, T., Sogacheva, L., Kuokka, S., Hillamo, R., Skorokhod, A., Belikov, I., Elansky, N., and Kerminen, V.- M.: Ion and particle number concentrations and size distributions along the TransSiberian railroad, Boreal Environ. Res., 12, 375-396, 2007.

Wang, S. C. and Flagan, R. C.: Scanning electrical mobility spectrometer, Aerosol Sci. Technol., 13, 230-240, 1990.

Wiedensohler, A.: An approximation of the bipolar charge distribution for particles in the submicron size range, J. Aerosol Sci., 19, 387-389, 1988.

Winkler, P. M., Steiner, G., Virtala, A., Vehkamäki, H., Noppel, M., Lehtinen, K. E. J., Reischl, G. P., Wagner, P. E., and Kulmala, M.: Heterogeneous Nucleation Experiments bridging the scale from molecular ion clusters to nanoparticles, Science, 319, 1374, doi:10.1126/science.1149034, 2008.

Winklmayr, W., Reischl, G. P., Lindner, A. O., and Berner, A.: A new electromobility spectrometer for the measurement of aerosol size distributions in the size range from 1 to $1000 \mathrm{~nm}$, J. Aerosol Sci., 22, 289-296, 1991.

Yli-Juuti, T., Riipinen, I., Aalto, P. P., Nieminen, T., Maenhaut, W., Janssens, I. A., Claeys, M., Salma, I., Ocskay, R., Hoffer, A., Imre, K., and Kulmala, M.: Characteristics of new particle formation events and cluster ions at K-puszta, Hungary, Boreal Environ. Res., 14, 683-698, 2009. 